\title{
Review Article \\ Harvesting Ambient Environmental Energy for Wireless Sensor Networks: A Survey
}

\author{
Gongbo Zhou, Linghua Huang, Wei Li, and Zhencai Zhu \\ School of Mechanical and Electrical Engineering, China University of Mining \& Technology, Xuzhou, Jiangsu 221116, China \\ Correspondence should be addressed to Gongbo Zhou; zhougongbo1985@163.com
}

Received 18 March 2014; Accepted 12 May 2014; Published 12 June 2014

Academic Editor: Ignacio R. Matias

Copyright ( 2014 Gongbo Zhou et al. This is an open access article distributed under the Creative Commons Attribution License, which permits unrestricted use, distribution, and reproduction in any medium, provided the original work is properly cited.

\begin{abstract}
In recent years, wireless sensor networks (WSNs) have grown dramatically and made a great progress in many applications. But having limited life, batteries, as the power sources of wireless sensor nodes, have restricted the development and application of WSNs which often requires a very long lifespan for better performance. In order to make the WSNs prevalent in our lives, an alternative energy source is required. Environmental energy is an attractive power source, and it provides an approach to make the sensor nodes self-powered with the possibility of an almost infinite lifetime. The goal of this survey is to present a comprehensive review of the recent literature on the various possible energy harvesting technologies from ambient environment for WSNs.
\end{abstract}

\section{Introduction}

In recent years, with the development of microelectronics and wireless communication technology, WSNs, as one of the world's ten top technologies in the 21st century, are a hot research field at home and abroad for the importance in the national defense and military applications $[1,2]$, environment monitoring [3], healthcare $[4,5]$, traffic control [6], industrial monitoring [7], target tracking [8], structural health monitoring [9], and so forth. WSNs are usually composed of many low-cost low-power microsensor nodes which are spread in a certain area aiming at collecting and processing the required data and transmitting them to a base station cooperatively by a wireless communication method. And by now the batteries are employed to provide energy for WSNs which is intended to operate for a very long time like several years or decades in many cases [10]. However, due to the limitation of node size, the energy provided by battery is very limited which cannot meet the requirement [11]. As a result, power supply, a limiting factor to the lifetime of sensor nodes, has become the bottleneck of development and application of WSNs.

The methods which have been studied to extend the life cycle of WSNs are related to two issues, namely, the energy supply and energy consumption. At present, low power consumption has almost become a core of research in WSNs like low-power MAC protocols $[12,13]$, routing protocols $[14,15]$ and transport protocols [16], and even operating systems [17] have also stressed the low power design, in order to prolong the life cycle of sensor network. But the nodes of WSNs cannot obtain a normal long-term operation only by all kinds of optimizing consumption approach for when the energy consumption has been reduced to a certain limit by all sorts of techniques, and then efforts will not get better results. Another issue is power supply. A nonrechargeable lithium battery is a promising energy storage device and the power density of it is $45 \mu \mathrm{W} / \mathrm{cm}^{3}$ for a one-year lifetime and $3.5 \mu \mathrm{W} / \mathrm{cm}^{3}$ for a ten-year lifetime [18]. If the sensor nodes are used for a suitable working environment with less demanding of size and running time, the chemical battery will become an economic choice. However, when WSNs are requested to work for a long time, the chemical battery cannot be the only energy source in many applications where a huge number of sensors are distributed or the place is extremely difficult to access for replacing or recharging the battery is an uneconomical or impossible behavior, such as biomedical field, environmental monitoring, and military applications $[19,20]$. So with the demand of exploring a new type of micropower to solve above problems, the microenvironmental energy harvesting technology has emerged. 
The energy existing in the natural environment is of many different kinds, wide distribution, and endless supply. And it can effectively alleviate the problem of wireless sensor nodes power supply and prolong the lifetime of WSNs to utilize the energy converted by a variety of environmental energy harvesting technologies. On the other hand, the total power cost of wireless sensor nodes has been reduced to $\mu \mathrm{W}$ level by now [21] with the development of microelectronics, low-power design, and network technology [22], and this makes a lot of energy harvesting systems becoming promising solutions to provide energy for WSNs. And with considering energy supply modules, the structure of wireless sensor nodes is shown in Figure 1.

Up to now, there have been some reports that the power of WSNs was provided by energy harvesting systems. For example, the solar harvesting device was tested in the alpine valleys to supply power for wireless sensor nodes. The test system consists of storage batteries, solar panels, and various control and test circuits. The test time started from the summer of 2005 and lasted for more than 100 days. The test site was chosen in the Alps for the weather conditions there are very poor as thunderstorms and rain clouds often occur. However, experimental results showed that the solar cells were able to provide a relatively stable electric power for sensor nodes [23].

Another case is carried out by the researchers of MictoStrain Company that their first solar-powered bridge monitoring devices was successfully installed in Corinth, Greek. Each sensor node and solar panel were encapsulated in the waterproof cover in order to improve the application environment in the outdoors. When any node monitored the vibration, the entire WSNs would receive warning [24].

The second solar-powered bridge monitoring WSN of MictoStrain Company, in cooperation with Dr. John Dewolf of Connecticut University, was installed in New London Goldstar Bridge. The system was used to monitor strain and temperature of the key bridge structures besides vibration. The sensor nodes were distributed throughout the bridge, and some places of which may be extremely difficult to access, so the battery replacement maintenance is not suitable for bridge monitoring application. The developed WSN system has overcome the above limitation by utilizing of solar energy harvesting device and achieved long-term monitoring of the bridge.

The micro generator PMG17 developed by subordinate Perpetuum Company of Southampton University converted mechanical vibration into electricity to provide power for the entire wireless sensor system by using elaborate designed resonant magnet and coil. The generated electricity was enough to supply energy for low-power wireless sensors through a variety of WSNs. The micro generator has been recognized by the oil industry and is being used in several gas stations including Shell Nyhamna gas plants in Norway to supply power for wireless vibration and temperature sensors. According to the shell, wireless vibration and temperature monitoring systems have been successful in pilot, Norway, which has opened up the way for wireless technology in global application as a standard.

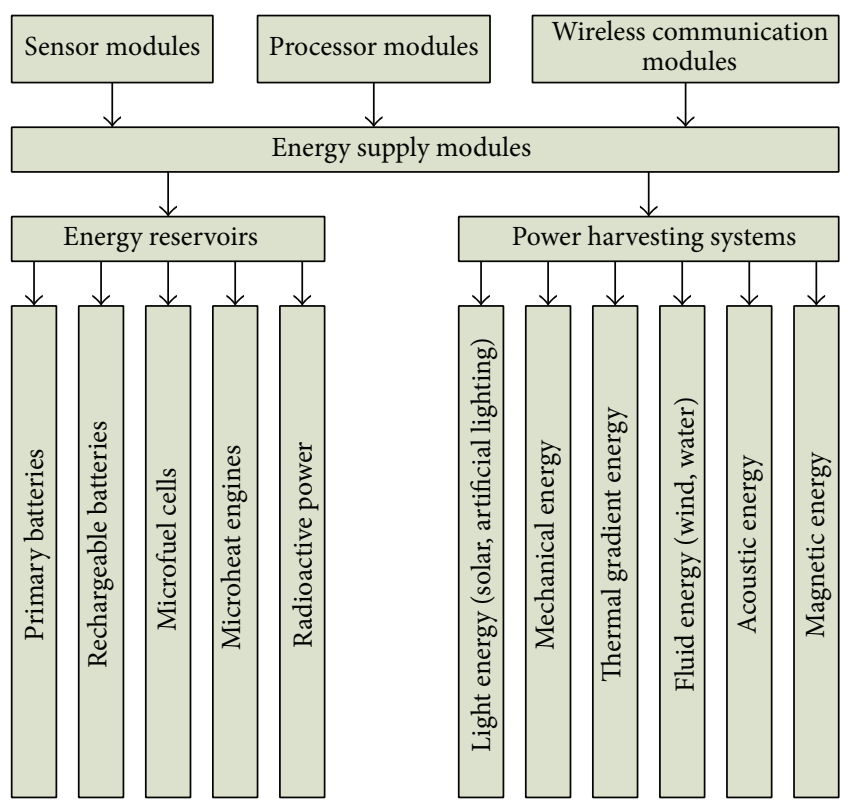

FIgURE 1: The structure of wireless sensor nodes.

The researchers of Takenaka Corporation developed a new WSN system which contains vibration energy harvesters and wireless sensors. The system is able to run without batteries and power lines for it can convert ambient mechanical vibration produced by people walking around and equipment operation into electrical energy. The system has been applied in technical institute of Takenaka Corporation for the office temperature and humidity regulation. The sensor nodes were powered by the converted microvibration energy of air conditioning ducts.

This paper is a survey of various possible solutions to harvest nonbiological energy from the environment for the WSNs as the part of power harvesting systems in Figure 1. The remainder of this paper is organized as follows. Section 2 presents the classification method of energy harvesting in this paper. Sections 3-9 give a comprehensive overview of the current state, ongoing research, and theoretical limits of many potential power sources from the environment for the WSNs. And Section 10 is the conclusion and future work.

\section{Sources of Energy Harvesting}

There is a variety of methods to harvest various energies in the ambient environment. The classification of energy harvesting in this paper is organized on the basis of the different forms of energy. And the energy sources reviewed in the paper include solar, mechanical, temperature gradient, dynamic fluid, acoustic, magnetic, and hybrid energy. For comparison, some examples of power outputs from energy harvesting technologies are listed in Table 1.

The general structure diagram of energy harvesting system of wireless sensors is shown in Figure 2 with the purpose of achieving stable long-term operation [33]. Thus we can utilize the available energy in the environment to generate electricity at any given location to supply power for 
TABLE 1: Comparison of power outputs from energy harvesting technologies.

\begin{tabular}{|c|c|c|}
\hline Harvesting method & Power density & References \\
\hline \multirow{2}{*}{ Solar energy-outdoors } & $15 \mathrm{~mW} / \mathrm{cm}^{3}$-bright sunny day & \multirow[b]{2}{*}[18]{} \\
\hline & $0.15 \mathrm{~mW} / \mathrm{cm}^{3}$ - cloudy day & \\
\hline Solar energy_indoors & $10-100 \mu \mathrm{W} / \mathrm{cm}^{2}$ & {$[21]$} \\
\hline Vibrations (piezoelectric-shoe inserts) & $330 \mu \mathrm{W} / \mathrm{cm}^{3}$ & {$[25]$} \\
\hline Vibrations (electrostatic conversion ) & $0.021 \mu \mathrm{W} / \mathrm{mm}^{3}-105 \mathrm{~Hz}$ & {$[26]$} \\
\hline \multirow{2}{*}{ Vibrations (electromagnetic conversion ) } & $184 \mu \mathrm{W} / \mathrm{cm}^{3}-10 \mathrm{~Hz}$ & {$[27,28]$} \\
\hline & $306 \mu \mathrm{W} / \mathrm{cm}^{3}-52 \mathrm{~Hz}$ & [29] \\
\hline Thermoelectric $-5^{\circ} \mathrm{C}$ gradient & $40 \mu \mathrm{W} / \mathrm{cm}^{3}$ & {$[30]$} \\
\hline Wind flow & $16.2 \mu \mathrm{W} / \mathrm{cm}^{3}-5 \mathrm{~m} / \mathrm{s}$ & {$[31]$} \\
\hline \multirow{2}{*}{ Acoustic noise } & $3 \mathrm{nW} / \mathrm{cm}^{3}-75 \mathrm{~dB}$ & \\
\hline & $960 \mathrm{nW} / \mathrm{cm}^{3}-100 \mathrm{~dB}$ & [18] \\
\hline Magnetic field energy & $130 \mu \mathrm{W} / \mathrm{cm}^{3}-200 \mu \mathrm{T}, 60 \mathrm{~Hz}$ & {$[32]$} \\
\hline
\end{tabular}

\begin{tabular}{|c|c|c|}
\hline $\begin{array}{l}\text { Environmental energy } \\
\text { harvesting system }\end{array}$ & $\begin{array}{l}\text { Adaptive intelligent } \\
\text { energy harvesting } \\
\text { management system }\end{array}$ & $\rightarrow \begin{array}{l}\text { Energy storage device } \\
\text { (batteries, capacitors, } \\
\text { supercapacitors) }\end{array}$ \\
\hline
\end{tabular}

Figure 2: The general structure diagram of energy harvesting system for wireless sensors in order to realize stable long-term operation.

wireless sensors. These energy sources include solar energy, mechanical vibration, temperature gradient, wind energy, water flow, and magnetic energy. The harvested energy can be used directly or stored into energy storage device according to the magnitude of output power and impedance. There is need to combine the design and fabrication with appropriate interface circuit for the purpose of realizing self-power of wireless sensors. In the rest of this paper, the harvesting methods are reviewed.

\section{Photovoltaics Power Generation}

There are two methods to extract solar power at present. One is solar thermal power generation which is suitable for large engineering systems and not applicable in WSNs for it is not available on small or nanoscale [34]. And the other is solar photovoltaic that is introduced in this paper. Solar energy is a constantly streaming power source, and utilizing solar energy to generate power is absolutely clean and nonpolluting, safe, reliable, of low failure rate, and not subject to regional restrictions.

In photovoltaic system, solar cells are used to convert sunlight into electrical power directly according to photovoltaic principle [21]. The other light such as fluorescent and infrared can also be used as the power source for solar cells [34]. According to the materials used, solar cells can be divided into four categories: silicon solar batteries, multicompound solar cells, polymer solar batteries (PPVC), and nanocrystalline solar cells. Now, the solar cells being used mainly include monocrystalline silicon cells, polycrystalline silicon cells, amorphous silicon cells (a-Si), and copper indium selenium cells, and which are being studied include nanotitanium dioxide sensitized cells, polycrystalline silicon thin-film cells, and organic solar cells. Among those, the silicon solar batteries are the most mature today in technology, which also have commercial value, especially the crystalline silicon solar battery. At present, polycrystalline silicon solar cells possess the largest production and market share, followed by monocrystalline silicon solar cells which are suitable for conditions of high-intensity light and outdoor spectrum [35]. The comprehensive comparison of various solar cells is shown in Table 2.

There are many methods for testing solar cells, while the quantum efficiency testing and volt-ampere characteristics testing are the most commonly used. They can not only get the spectral response analysis of solar cells, but also obtain the true value of the photocurrent, namely, the true shortcircuit current value of solar cells as shown in the following expression:

$$
I_{\mathrm{SC}(\mathrm{AMN})}=\int_{300}^{1100} P_{\mathrm{AMN}}(\lambda) \times S_{a}(\lambda) d \lambda,
$$

where $P_{\mathrm{AMN}}(\lambda)$ is the solar spectral irradiance of atmospheric quality as $N$ under the condition of a given standard in $\mathrm{W} / \mathrm{m}^{2}$. $\mu \mathrm{m}$ and $S_{a}(\lambda)$ is the absolute spectral response of solar cells.

Figure 3 shows the output characteristic curve of solar cells (Figure 3(a) shows the $I-V$ and $P-V$ characteristic curve of solar cells under constant sunshine and Figure 3(b) shows the $V$-A characteristic curve of solar cells under different sunshine). It can be seen that the solar cell is neither a constant voltage source nor a constant current source, but a nonlinear DC power supply. It can obtain the maximum output power, $P_{\max }$, while the value of load resistance is chosen to make the product of output voltage and current maximum. And the output power of solar cells will change greatly along with the change of sunshine intensity and ambient temperature. In order to improve the efficiency of the solar harvesting system and generate power as much as possible, the maximum power point tracking (MPPT) controller is needed in the system to make the solar cells always work in the maximum power point under different conditions of sunshine, temperature, and load characteristics [36]. 


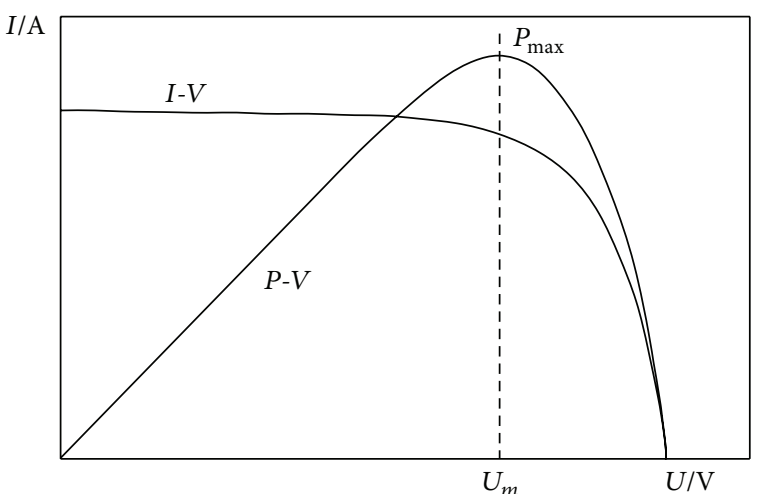

(a)

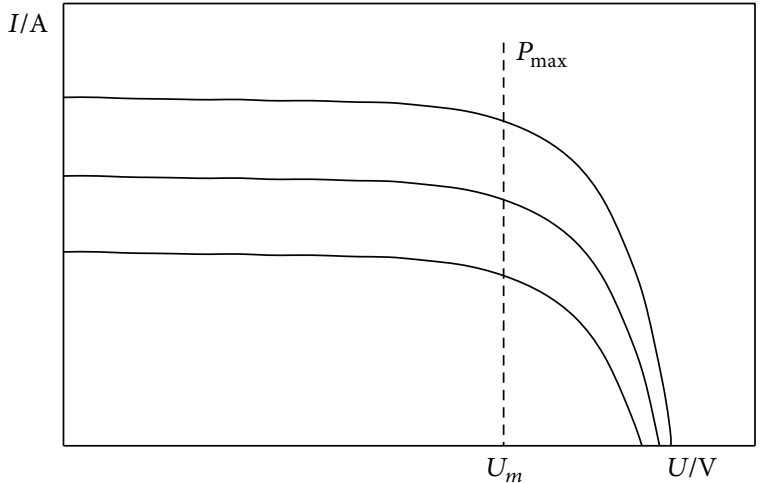

(b)

Figure 3: The output characteristic curve of solar cells: (a) the $I-V$ and $P-V$ characteristic curve of solar cells under constant sunshine; (b) the $V$-A characteristic curve of solar cells under different sunshine.

TABLE 2: The comprehensive comparison of various solar cells.

\begin{tabular}{|c|c|c|c|}
\hline Classification & Efficiency & Advantage & Disadvantage \\
\hline \multicolumn{4}{|l|}{ Silicon solar cells } \\
\hline Monocrystalline & $15-24 \%$ & $\begin{array}{l}\text { High conversion efficiency, the most mature } \\
\text { technology, and high reliability }\end{array}$ & $\begin{array}{l}\text { High cost, large silicon consumption, } \\
\text { and complex production process }\end{array}$ \\
\hline Polysilicon & $14-20.4 \%$ & $\begin{array}{l}\text { No efficiency recession, can be fabricated on } \\
\text { cheap substrates, and far lower cost than } \\
\text { monocrystalline }\end{array}$ & $\begin{array}{l}\text { Relatively large silicon consumption } \\
\text { and cost, complex production process }\end{array}$ \\
\hline $\mathrm{a}-\mathrm{Si}$ & $8-13.2 \%$ & $\begin{array}{l}\text { Low cost, easiness of mass production, } \\
\text { relatively high optical absorption coefficient, } \\
\text { very low dark conductivity, and good } \\
\text { response to weak light }\end{array}$ & $\begin{array}{l}\text { Light-induced recession effect, low } \\
\text { conversion efficiency, and low stability }\end{array}$ \\
\hline \multicolumn{4}{|l|}{$\begin{array}{l}\text { Multicompound } \\
\text { solar cells }\end{array}$} \\
\hline $\mathrm{CdS}$ & Up to $16 \%$ & Low cost, easiness of mass production & Toxic cadmium \\
\hline $\mathrm{CdTe}$ & Theoretical: $28 \%$ & $\begin{array}{l}\text { Ideal band gap, high light absorption rate, } \\
\text { high conversion efficiency, stable } \\
\text { performance, simple structure, and low cost }\end{array}$ & $\begin{array}{l}\text { Limited natural tellurium reserves, } \\
\text { high cost of module and base material, } \\
\text { and toxic cadmium }\end{array}$ \\
\hline GaAs & Up to $30 \%$ & $\begin{array}{l}\text { High light absorption coefficient and } \\
\text { conversion efficiency, strong resistant of } \\
\text { temperature }\end{array}$ & Too high cost \\
\hline CIGS & Up to $20 \%$ & $\begin{array}{l}\text { Low cost, nonrecession, good weak light } \\
\text { performance, wide applicability of substrate, } \\
\text { adjustable optical band gap, and strong } \\
\text { antiradiation ability }\end{array}$ & $\begin{array}{l}\text { Rare materials, the difficulty of } \\
\text { controlling four elements precisely }\end{array}$ \\
\hline PPVC & Below 5\% & $\begin{array}{l}\text { Excellent mechanical properties and } \\
\text { film-processing ability, low cost, flexibility, } \\
\text { and simple manufacture }\end{array}$ & $\begin{array}{l}\text { Low conversion efficiency, } \\
\text { unstable performance }\end{array}$ \\
\hline $\begin{array}{l}\text { Nanocrystalline } \\
\mathrm{TiO}_{2} \text { solar cells }\end{array}$ & More than $10 \%$ & $\begin{array}{l}\text { Simple manufacture, low cost, good stability, } \\
\text { nontoxicity, and short energy recovery cycle }\end{array}$ & $\begin{array}{l}\text { Low conversion efficiency, immature } \\
\text { research and development }\end{array}$ \\
\hline
\end{tabular}

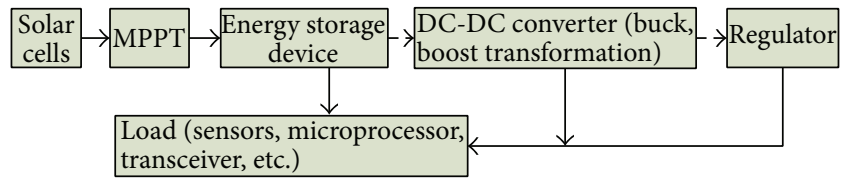

FIGURE 4: The general block diagram of solar energy harvesting system for wireless sensors.
The general block diagram of solar energy harvesting system for wireless sensors is shown in Figure 4.

The energy storage device is used to store generated energy as well as buffering the power required by sensor nodes [37]. The wireless sensors can be connected to energy storage device directly for its DC characteristics. While the voltage range of each sensor node may not be the same and 
some sensors may be very sensitive to the change of voltage supply, then the output voltage needs to be regulated by DCDC converter [38]. However, sometimes this method is not advisable with considering the simplicity and efficiency of energy harvesting system. The additional regulation may also be required between sensor and energy storage device to ensure that the sensor node works with a stable and safe voltage.

Solar energy has been more widely considered for WSNs which consume several $\mathrm{mV}$ of energy [39] as it is common and accessible energy in the majority of deployment environments and can be easily tapped [40]. While it is designed as a power source for WSNs, the first thing which we must consider is the power supply requirements of WSNs. Then, we must take into account the impact of these factors on the efficiency of solar cells, such as solar insolation, period of dense cloud and snow cover, shade caused by obstructions, effects of season, latitude and elevation, the angle and position at which the solar panel installed, characteristics of the solar cells, power conditioning features, and the chemistry and capacity of energy storage components used to store the harvested energy [41-43].

With the cost of optoelectronic components declining, it has become a reasonable solution to utilize solar energy source for WSNs [44]. At present solar cells with high efficiency are available in market and have several remote sensing and wireless applications [45]. And the photovoltaic technology has developed into particles deposition on the photosensitive substrate from the initial silicon manufacturing. Having the advantages of light weight, easy installation, and reduced influence of the environmental temperature, this new material can be used both indoor and outdoor and it is very suitable for providing power for small and remote sensors.

Recently, researchers have made a lot of breakthroughs of micro solar cells and some of them are shown in the following.

The company of Kyosemi developed a micro spherical solar cell called Sphelar which is a revolutionary transformation compared to the previous solar cell [46]. The main characteristic of this product is ability to capture all directions of sunshine and accept more than $20 \%$ of the indirectly reflected light. The overall efficiency is far more than most of the flat solar panels and the general requirement of area is less. But the design and production of this solar cell are also more complicated.

Canadian scientists developed a new kind of efficient full spectrum solar cell with tandem-type connection based on colloidal quantum dots (CQD) and the theoretical conversion efficiency is as high as $42 \%$ [47]. The solar cell consists of two absorbing layers such that one layer is used to capture the visible sunlight and another is able to catch the invisible sunlight. This progress provides a feasible way to maximize the capture of a variety of light emitted by the sun and it is promising to improve the conversion efficiency and lower the cost. The researchers hope this new battery can be integrated into building materials, mobile phones, and automotive parts in 5 years.

Traditional thin-film solar cells have a theoretical limit of light-harvesting ability called "ray-light intensity extreme" which indicates the maximum amount of light can be captured by a material, but this peak value can be reached only when the material reaches a certain thickness. However, the researchers of California Institute of Technology found that when the film thickness is equal to or less than the wavelength of visible light, the light-harvesting capacity of the film will become very strong. This progress is helpful to develop a new battery with the thickness of only one percent of the current commercial thin-film solar cells. At present, researchers have developed a thin-film battery with thickness of a few tenth of nanometer [48]. But a lot of light will penetrate through this thin-film battery before being absorbed by it. And this technology is also facing many other challenges, such as the need for additional industrial processes to manufacture these thin films, which will result in increased costs.

Recently, the Australian and Japanese scientists invented a solar cell which is thinner than spider web [49]. This ultrathin solar cell is composed of electrodes which are embedded in the plastic tab and the thickness is only 1.9 microns which is equivalent to one tenth of the current thinnest solar battery. This ultrathin, superlight, ultraflexible solar cell will be widely used in the future, including the use for portable electronic charging device or in the manufacture of electronic textiles. Now the researchers are increasing the photoelectric conversion efficiency of it. In addition, they are also trying to increase the size of the new solar cell for the power generation capacity of solar cell is proportional to the size. This new solar cell will be put into use within five years.

The solar panel is modular and can be utilized on any scale to achieve the power desired. It can still generate some power when there is dense cloud in sky for the ability of convert emitted light. In addition, the panels require almost no maintenance and have a typical lifetime of about 20 years [34]. The disadvantage of utilizing photovoltaic systems is that the harvested energy is proportional to the surface area of solar panels and in order to enable the nodes get as much energy as possible, it is needed to increase the surface area of solar panel which is in contradiction with the miniaturization requirements of the sensor nodes. And the weather conditions and position where photovoltaic cell is installed play key roles. Commonly, the average available harvested power is very low.

The harvested energy is proportional to the surface area of solar panels, so the main ongoing research is improving the efficiency of existing photovoltaic materials and developing new photovoltaic material with high efficiency such as black silicon. While the above is the step-by-step thing, maybe the most important thing at present is that efficiently making use of the heat energy of solar radiant energy. Otherwise, the dissipation and the undesired temperature rise of solar cells will cause the reducing of open circuit voltage, conversion efficiency and lifetime of solar cells.

\section{Mechanical Energy Harvesters}

The mechanical energy is generated when an object is subjected to some movement or mechanical deformation and it can be converted into electrical energy by several methods 
TABLE 3: The energy harvesting method corresponding to different vibration sources.

\begin{tabular}{ll}
\hline The form of vibration sources & Energy harvesting method \\
\hline Force excitation & $\begin{array}{l}\text { Piezoelectric energy harvesting } \\
\text { method }\end{array}$ \\
Velocity excitation & $\begin{array}{l}\text { Electromagnetic energy } \\
\text { harvesting method }\end{array}$ \\
Displacement excitation & $\begin{array}{l}\text { Piezoelectric electrostatic energy } \\
\text { harvesting method }\end{array}$ \\
\hline
\end{tabular}

including piezoelectric, electrostatic, and electromagnetic conversion [42]. The vibration is the most prevalent energy source for it is available in many environments including buildings, roads, bridges, vehicles, ships, and other kinds of production and living facilities [50]. And in the biomedical sciences, the mechanical energy harvesters can also be utilized to provide energy for biological sensors which are used to real-time monitor parameters like blood pressure and blood-sugar levels, and so forth, of human or animals by taking advantage of body pulse and blood current.

In the ambient environment, the main vibration frequency range is $60 \mathrm{~Hz}-200 \mathrm{~Hz}$ and the acceleration peak is between $0.5 \mathrm{~m} / \mathrm{s}^{2}$ and $10 \mathrm{~m} / \mathrm{s}^{2}$ [35]. According to the force excitation and basic excitation (displacement and velocity), vibration sources act on the vibration energy harvesting system which converts the mechanical energy into electrical energy as shown in Table 3.

4.1. Piezoelectric Energy Harvesters. With the improvement of piezoelectric materials, piezoelectric properties, and the use of highly integrated, low-power electronic devices, the piezoelectric harvesting technology has received extensive attention in recent years. And it is an inherent property of piezoelectric materials that generate electricity when pressure is applied [51]. Piezoelectric transduction is generally well suited to the reciprocating nature of the motions instead of rotating systems [52]. Piezoelectric materials mainly include piezoelectric monocrystal, piezoelectric ceramics, piezoelectric polymers, and piezoelectric composites. At present, piezoelectric ceramic PZT is the most commonly used piezoelectric materials for the piezoceramics have the advantages of mature manufacturing process, low cost, large electromechanical coupling constants, and high energy conversion rate. But piezoelectric ceramic PZT is fragile and unable to bear large strain, and it is easy to produce fatigue crack and brittle fracture on the impact of high-frequency cyclic load. Another commonly used piezoelectric material is polyvinylidene fluoride (PVDF). Compared to piezoelectric ceramic PZT, PVDF has smaller electromechanical coupling constants [53], but it has advantages of good flexibility, high mechanical strength, good fatigue resistance, and chemical stability [54] and is suitable for the application with under the high-frequency periodic load. Table 4 lists some performance parameters of the commonly used piezoelectric ceramic PZT and PVDF.

An expression of average harvested power from piezoelectricity-based vibration has been presented by Shu and it is shown in the following for the standard and SSHI interface, respectively [55]:

$$
\begin{aligned}
\bar{P}= & \frac{P}{F_{0}^{2} / \omega_{\mathrm{sc}} M}=\frac{1}{(r \Omega+\pi / 2)^{2}} \\
& \times\left(k_{e}^{2} \Omega^{2} r\right) \\
& \times\left(\left(2 \zeta_{m}+\frac{2 k_{e}^{2} r}{(r \Omega+\pi / 2)^{2}}\right)^{2} \Omega^{2}\right. \\
& \left.\quad+\left(1-\Omega^{2}+\frac{k_{e}^{2} r \Omega}{r \Omega+\pi / 2}\right)^{2}\right)^{-1}, \\
\bar{P}^{\mathrm{SSHI}}= & \frac{P^{\mathrm{SSHI}}}{F_{0}^{2} / \omega_{\mathrm{sc}} M}=\left(\frac{1}{\left(\left(1-q_{I}\right) / 2\right) r \Omega+\pi / 2}\right)^{2} \\
& \times\left(k_{e}^{2} \Omega^{2} r\right) \\
& \times\left(\left(2 \zeta_{m}+\frac{2\left[1+(r \Omega / 2 \pi)\left(1-q_{I}^{2}\right)\right] k_{e}^{2} r}{\left(\left(\left(1-q_{I}\right) / 2\right) r \Omega+\pi / 2\right)^{2}}\right)^{2} \Omega^{2}\right. \\
& \left.\quad+\left(1-\Omega^{2}+\frac{\left(\left(1-q_{I}\right) / 2\right) k_{e}^{2} r \Omega}{\left(\left(1-q_{I}\right) / 2\right) r \Omega+\pi / 2}\right)^{2}\right)^{-1},
\end{aligned}
$$

where $F_{0}$ is the constant magnitude, $\omega_{\mathrm{sc}}$ is the natural oscillation frequency (of the piezoelectric vibrator under the short circuit condition), $\zeta_{m}$ is the mechanical damping ratio, $\Omega$ and $r$ are the normalized frequency and electric resistance, respectively, $k_{e}^{2}$ is the alternative electromechanical coupling coefficient, $M$ is the oscillating proof mass, and $q_{I}=e^{-\pi / 2 Q_{I}}$, where $Q_{I}$ is the inversion quality factor due to the energy loss mainly from the inductor in series with the switch.

The equation shows that the generated power depends on the frequency and acceleration of input vibration, the electrical load, the oscillating proof mass, the natural frequency, the mechanical damping ratio, the electromechanical coupling coefficient of the system, and the inversion quality factor in the SSHI circuit. It can be used to compare power harvesting devices of various sizes and with different vibration inputs to estimate efficiencies.

There are two practical piezoelectric coupling modes for operation as shown in Figure 5. In the d33 mode, the vibration force is applied in the same direction as the poling direction, while in the $\mathrm{d} 31$ mode the force is applied perpendicular to the poling direction [56, 57]. The $\mathrm{d} 33$ mode has a higher coupling coefficient than $\mathrm{d} 31$ mode, but $\mathrm{d} 31$ mode is able to produce a larger strain in a small external force at very low voltage source and small-sized devices compared to $\mathrm{d} 33$ mode, and it allows piezoelectric material to be strained on a bending cantilever [58], so it is more suitable for energy harvesting of wireless sensor networks.

Piezoelectric transducer is one of the key structures in piezoelectric energy harvesting system and the selection of it had better be consistent with the environmental vibration so 
TABLE 4: The basic properties comparison of the commonly used piezoelectric materials.

\begin{tabular}{lccccc}
\hline Material & $\mathrm{Tc} /{ }^{\circ} \mathrm{C}$ & $\varepsilon 33 / \varepsilon 0$ & $\mathrm{~d} 33(\mathrm{pC} / \mathrm{N})$ & $\mathrm{g} 33\left(10^{-3} \mathrm{Vm} / \mathrm{N}\right)$ & $\mathrm{d} 33 \cdot \mathrm{g} 33\left(1015 \mathrm{~m}^{2} / \mathrm{N}\right)$ \\
\hline PZT-4 & 328 & 1300 & 289 & 25.1 & 7253.9 \\
PZT-5H & 193 & 3400 & 593 & - & - \\
PZT-8 & 300 & 1000 & 218 & - & - \\
PVDF & 41 & 13 & -33 & -339.0 & 11187 \\
\hline
\end{tabular}

TABLE 5: The structures and characteristics of piezoelectric transducers.

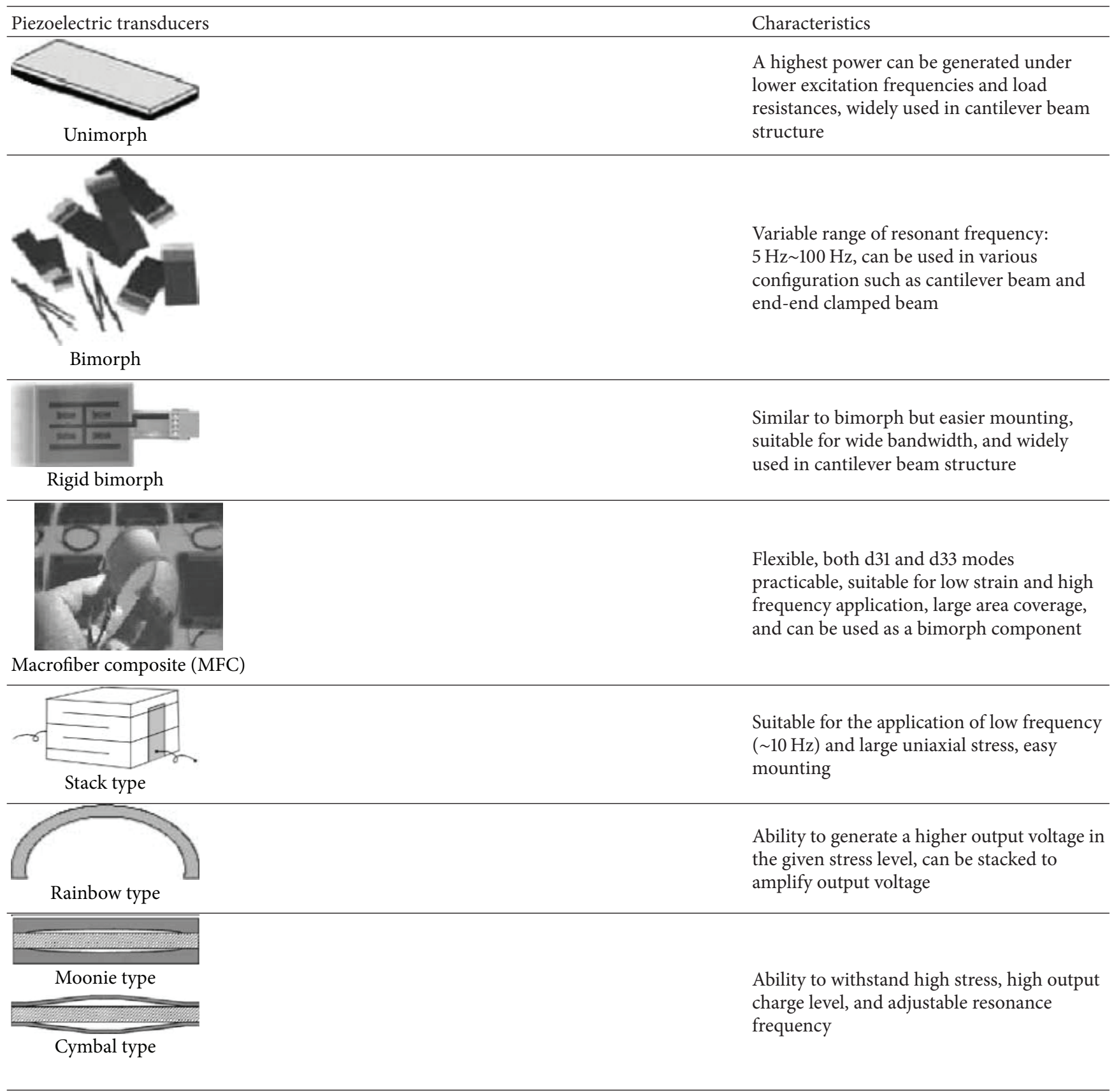




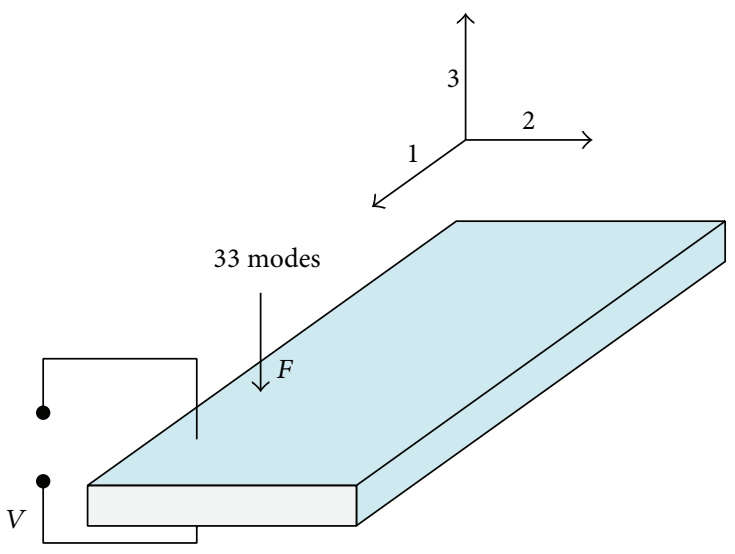

(a)

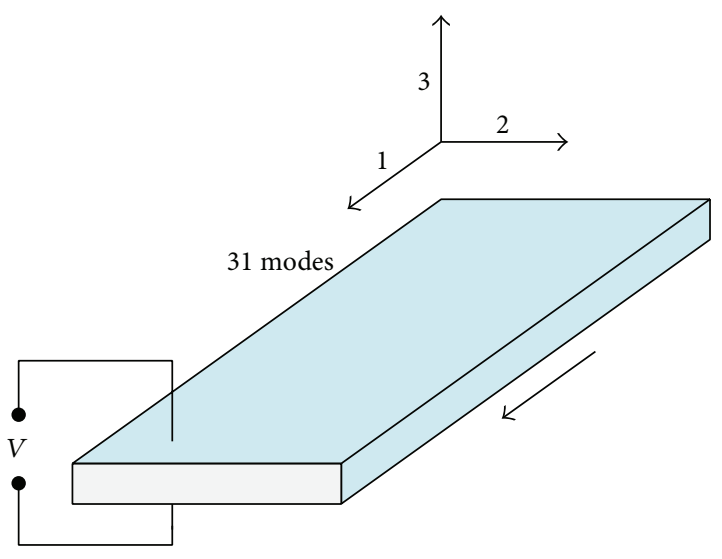

(b)

FIGURE 5: Illustration of (a) $d_{31}$ mode; (b) $d_{33}$ mode.

as to maximize the harvesting of mechanical energy. According to the different structures, piezoelectric transducers can be divided into unimorph, bimorph, rainbow type, cymbal type, moonie type, stack type, and so forth [56, 57, 59-63]. Table 5 shows the typical structures and characteristics of piezoelectric transducers.

Among the vibration-based MEMS piezoelectric energy harvester, the cantilever beam is the most widely used structure for cantilever beam can produce the maximum deflection and compliance constant [64]. At the same time, the bending vibration frequency of the beam is usually lower than its longitudinal vibration frequency and torsional vibration frequency and it is easily excited. So many piezoelectric transducers are applicable to this structure. Rectangle-shaped cantilever structures are the most commonly used due to the simple process and relatively high efficiency. Having a free small end, the trigon-shaped cantilever beam will produce a higher output power for the higher strains and maximum deflections than the rectangular beam with width and length equal to the base and height of the triangular beam [65], while the strain can be more distributed throughout the trapeziumshaped cantilever structure[66] which can deliver much more energy than a trigon-shaped beam with the same PZT volume [67].

Chen et al. presented a circular-diaphragm-structural PZT energy harvester with a dimension of $\Phi 30 \times 0.4 \mathrm{~mm}^{2}$ [68]. They found the maximum output voltage and power improve at relatively low frequency with the increase of prestress and there exists an optimal contacting area between the mass and piezoelectric diaphragm and a power of $12 \mathrm{~mW}$ is generated. The technology is difficult to integrate with MEMS technology and batch-oriented manufacture. The amount of the harvested energy is potential to power wireless sensors and the harvester can be integrated with sensors utilizing an external force with a circular diaphragm structure, such as pressure sensor, to realize self-power.

Chang et al. developed a direct-write piezoelectric polymeric nanogenerator with the peak and average energy conversion efficiency of $21.8 \%$ and $12.5 \%$, respectively [69]. The electrical outputs can be enhanced by increasing the strain rate and frequency and the serial or parallel connections of nanogenerator. The nanogenerator provides several advantages including high efficiency, manufacturability, and the capability of direct integration with other structures and processes. Nonetheless, the complexity of electrospinning process results in low-rise repeatability at present. The nanogenerator can be used by direct-writing nanofibers onto a large area cloth to increase the total power output for portable electronics and wireless sensors.

The advantages of piezoelectric energy harvesting devices are simple structure, low cost, no fever, no electromagnetic interference, easiness to manufacture, relatively high output voltage level, electromechanical conversion efficiency, and so forth [70]. But the cantilever beam which is the most used structure in the piezoelectric harvesting system could not meet the complicated external environment and the situation with wide exciting vibration band. The defects limit the application of piezoelectric harvesting system to a certain degree. In addition, the piezoelectric harvesting system can produce a high level of output energy only when it generates resonance with external vibration excitation. And it usually requires energy harvesting circuit to modulate the output power, which leads to a relatively large energy loss due to the switch control circuit and it greatly affects the efficiency of energy harvesting system.

In order to obtain better performance and improve the efficiency as well as practicability of piezoelectric energy harvester, the ongoing research mainly includes improving the existing piezoelectric materials property, researching new piezoelectric materials with large piezoelectric constant strain, high electromechanical coupling coefficient and low loss, and improving the structure of piezoelectric energy harvester to increase the output power. Among them, the most important point is that researching the piezoelectric energy harvesting with features of multimodal and wide band to meet the unknown or time-changing external excitation and wide band vibration.

4.2. Electrostatic (Capacitive) Energy Harvesting. Electrostatic energy harvesting system generates voltage by changing 
the capacitance. Before the energy is outputted by the system, it is needed to apply an initial voltage to the capacitance [71]. And when the quantity of charge stored in the capacitor was changed by the external vibrations, a charge flow is generated in the circuit and thus provides electrical power to the sensors. Compared with other vibration energy harvesting methods, the electrostatic energy harvesting device has very good compatibility with IC and MEMS technology [72], and it can take advantage of the relatively mature silicon micromachined technology to fabricate MEMS variable capacitor [73-75] which has many advantages such as high Q, wide tuning range, low noise, small size, and low quality and is more suitable for wireless sensors.

Sidek et al. designed and simulated an SOI-MEMS electrostatic vibration energy harvester with the size of micron level using the architect module with CoventorWare 2010 [76]. Simulation results show that the harvester is capable of generating power of $5.891 \mu \mathrm{W}$ at the resonant frequency of $2 \mathrm{kHz}$ which is too high compared to the frequency of ambient vibration. However, the required performance and manufacturing capability can be achieved by compromising the structural design and fabrication process.

Sheu et al. developed an in-plane, gap overlap combdrive electrostatic vibration energy harvester with a mass of $4.9 \mathrm{mg}$ to deliver an average output power of $0.0924 \mu \mathrm{W}$ when harvesting $10 \mu \mathrm{m}$ amplitude of motion at $105 \mathrm{~Hz}$ and the size of the harvester is $3000 \mu \mathrm{m} \times 3000 \mu \mathrm{m} \times 500 \mu \mathrm{m}$ [26]. The harvester is implemented by CMOS process making the onchip integration of signal conditioning circuit feasible. The harvester has a very small size, but the energy harvested is also at a very low level targeted only at very low power applications.

Altena et al. presented an electret-based MEMS electrostatic energy harvester [77]. Experimental results showed that the practical power output with polarization voltage differs with expected quadratic behavior. The use of the electret in this paper not only solved the common issue of capacitive energy harvesters with the necessity of an auxiliary energy reservoir, but also introduced some questions that the measured output of the device showed a step-like behavior which is more pronounced with increasing of the polarization voltages for the reason of the lateral electrostatic forces limiting the movement of the seismic mass.

Although the electrostatic energy harvesting systems have very good compatibility with IC and MEMS technology and a higher voltage and power density in the same size, the initial voltage or charge of variable capacitor is one of the key problems that needs to be solved [78]. The use of external power source for charging the capacitor is against the original intention of the energy harvesting [79]; therefore it is necessary to utilize the stored energy of the electrostatic energy harvesting system itself to provide the initial voltage or charge for capacitor. And electret, as an electrostatic guiding, which can be divided into two categories: $\mathrm{SiO}_{2}$-based inorganic electret and polymer-based organic electret, is one of the effective methods to solve the problem $[80,81]$ through three methods of corona charging, electric breakdown charging, and liquid contact charging. The comparison of the three charging method is shown in Table 6.

A major research effort on an electret-based energy harvester with a single silicon structure has been undertaken by Fujii et al. [82]. The authors used the fabricated counter electrode for the grid electrodes which can charge the electret after the fabrication. And they fabricated the harvester with unidirectionally flexible Si spring which is suitable for converting low frequency vibration. The harvester can achieve a maximum output power of $0.23 \mu \mathrm{W}$ with an acceleration of $0.1 \mathrm{G}$ at $10 \mathrm{~Hz}$.

As a widely used dielectric medium with electricity storage function, electret materials have been integrated into many MEMS devices with the development of MEMS technology in these years. But the miniaturization of the electret goes along with the disadvantages of low surface potential, poor stability, and so forth [83]. And it is one problem that needs to be solved urgently.

The initial voltage or charge of variable capacitor is a major factor technical problem restricting the development of MEMS electrostatic energy harvesting system, so a main ongoing research is effective using storage energy of electrostatic energy harvester to supply stable initial voltage for capacitor, such as researching high-performance electret materials. In addition, many researchers focus on reducing the frequency and improving the electromechanical coupling performance of electrostatic vibration energy harvester in order to further its output power and practicability.

\subsection{Electromagnetic Energy Harvesting. Electromagnetic} Energy Harvesting is based on the well-known principle of electromagnetic induction which is defined as induced electromotive force which will be generated in a conductor when the magnetic flux is changing around it. The electromagnetic vibration energy harvesters can be simply packaged to reduce the risk of corrosion and eliminate the temperature limit. The relevant parameters about harvesters include magnetic induction, magnetic flux density, coercive force. And commonly, there are four available magnets: ceramic, Alnico, SmCo, and NdFeB. Table 7 lists some of their performance parameters. As in the same volume, $\mathrm{NdFeB}$ has the largest magnetic field intensity, high coercive force, and no demagnetization due to the vibration of generator, so it is the most commonly used permanent magnetic material in recent years [84].

The deposition and forming of magnets can be achieved by microprocessing technology. Sputtering and electroplating and other deposition technologies have been used to fabricate the micromagnet. However, the characteristics of permanent magnets decrease with the magnet thickness reduced, so the manufacture of high-quality micromagnet is very difficult [85]. To replace the separate magnets with micromachined permanent magnets is one problem which needs to be solved in the micro electromagnetic energy harvesting systems.

Rahimi et al. presented a vibration-based electromagnetic (EM) energy harvester system powering a $1.5 \mathrm{~V}, 15 \mu \mathrm{A}$ load with $65 \%$ conversion efficiency, and $5 \%$ ripple, at an external vibration frequency of $10 \mathrm{~Hz}$ and the maximum 
TABLE 6: The comparison of three charging methods.

\begin{tabular}{lccc}
\hline Charging method & Device complexity & Control difficulty & Surface potential \\
\hline Corona charging & Simple & Easy & Large \\
Electric breakdown charging & Rather complex & Rather difficult & Small \\
Liquid contact charging & Complex & Difficult & Small \\
\hline
\end{tabular}

TABle 7: Performance parameters of typical magnetic materials.

\begin{tabular}{lcccccc}
\hline Material & $\mathrm{B} / \mathrm{mT}$ & $(\mathrm{BH}) \mathrm{max} /\left(\mathrm{kJ} / \mathrm{m}^{3}\right)$ & $\mathrm{Hc}$ & $\mathrm{Tc} /{ }^{\circ} \mathrm{C}$ & Max. operating temperature $/{ }^{\circ} \mathrm{C}$ & $\mathrm{Density} /\left(\mathrm{kg} / \mathrm{m}^{3}\right)$ \\
\hline Ceramics & 100 & 26 & High & 460 & 250 & 4980 \\
Alnico & 130 & 42 & Low & 860 & 550 & 7200 \\
SmCo $(2: 17)$ & 350 & 208 & High & 750 & 300 & 8400 \\
NdFeB $(\mathrm{N} 38 \mathrm{H})$ & 450 & 306 & High & 320 & 120 & 7470 \\
\hline
\end{tabular}

output power is $22.5 \mu \mathrm{W}$ [86]. The separation of the magnet from the other part of the system raises problems such as misalignment and low manufacturability while the author employed a boot-strap rectifier in this technique which can reduce the power losses due to the diode threshold voltage drops during AC/DC conversion compared to conventional rectifiers. Since most environmental mechanical vibrations arise at low frequency $(1-10 \mathrm{~Hz})$, this technology offers the possibility to harvest energy in many applications such as wearable electronics and earthquake warning systems.

Tao et al. proposed a micro electromagnetic vibration energy harvester with dimension of $4.5 \times 4.5 \times 1 \mathrm{~mm}^{3}$ and the total volume of the harvester is about $20 \mathrm{~mm}^{3}$ [87]. Testing results showed that the harvester was able to generate a maximum peak-peak voltage of $20.9 \mu \mathrm{V}$ at the device's resonance frequency of $365 \mathrm{~Hz}$ and input acceleration of $1 \mathrm{~g}$. This study offers a solution of the micro electromagnetic harvester fully integrated with MEMS fabrication technology though the produced energy is very limited.

The electromagnetic generators have the advantage of improved reliability and reduced mechanical damping for there would not be any mechanical contact between any parts. Also, no separate voltage source is required. The extracted electric power of electromagnetic energy harvester is related to electromagnetic damping which depends on flux gradient, coil turns, coil impedance, and load impedance and these parameters are all connected with the size. The earlier electromagnetic energy harvester is complex and bulky [87], while the MEMS technology has been widely studied in the electromagnetic energy harvesting structures now. However, the miniaturization also has brought some problems such as field reduction, reduced coil varieties, and decreased power extraction capacity.

The miniaturization of electromagnetic energy harvester comes along with decreasing output power, and the main factors influencing the efficiency of energy harvesting are magnet and coil, so the present study points are reducing the device size under the premise of not affecting energy harvesting efficiency, improving coil manufacturing technique, developing good toughness, resistant-impact, low-cost coil base material, and producing high-performance tiny magnets. In addition, many researchers focus on automatic adjusting of electromagnetic energy harvester resonance frequency according to the change of external vibration source in order to improve the efficiency of energy harvesting.

The three methods of harvesting mechanical energy have different advantages and disadvantages in the field of power density, integration with MEMS and IC technology, electrical matching, and so on, but the efficiency of them is related to the vibration frequency due to the mathematical fact that the maximum power output from vibration-based generators is proportional to the cube of the vibration frequency and drops dramatically at low frequencies $(1-100 \mathrm{~Hz})$ [27, 28]. Because the main frequencies in the environment are relatively low, the mechanical energy harvester may need to utilize the upconverter to transform the low frequency into high frequency to achieve an increased power output $[27,28]$. Among the three mechanical energy harvesting methods, the piezoelectric and electrostatic harvesters have the ability to generate voltage ranging from 2 to $10 \mathrm{~V}$, but the electromagnetic harvesters can only produce a maximum voltage of $0.1 \mathrm{~V}$ [41].

The external excitations are random for vibration energy harvesting systems, so it is hoped that the systems are able to have a better response towards vibration excitations with different frequencies and amplitudes in order to ensure the energy harvesting efficiency. So it is necessary to comprehensively consider two factors including system output power and bandwidth of the resonant region and select the appropriate system parameters when the system damping ratio is designed. In order to maximize the generated energy, the below basic principles should be followed during the design of vibration energy harvesting systems.

(1) The frequency of vibration energy harvesting system should be the same with the external excitation frequency in order to reach resonance.

(2) It should be tried to increase the quality of inertial components in the permit of system [88].

(3) It should be tried to increase the relative motion transmissibility for the vibration energy harvesters with determined structure in the case of constant external excitation level. 
(4) It should be tried to decrease the damping ratio of the system for the vibration energy harvesters with a given mass of the inertial components under the premise of guaranteeing a certain bandwidth of the system resonance region.

\section{Thermoelectric Generators}

The temperature difference between the two ends of semiconductor PN junction is used to generate power by micro thermoelectric power generation system. Thermoelectric materials have three temperature-dependent properties: Seebeck coefficient, thermal conductivity, and electrical conductivity [89]. There are many sources of waste heat which can be used around us, such as geothermal [90], industrial waste heat, engine exhaust and the heat of sun [91].

The conversion efficiency of current thermoelectric generators (TEGs) is commonly between $6 \%$ and $11 \%$. The efficiency of TEGs is approximately proportional to temperature difference when it is small while both of thermoelectric materials and temperature difference have a strong influence on the output voltage, and the generated voltage is proportional to the number of thermoelectric elements and the temperature difference when the thermoelectric materials is selected. Because it is difficult to maintain a significant temperature gradient on a small device [92], the small available temperature difference between the surfaces of the TEG, commonly no higher than $10^{\circ} \mathrm{C}$ [93], and the micro size of the devices [94] make the output power and the conversion efficiency very limited. In addition, there is an efficiency cap governed by the Carnot cycle of energy harvested from a temperature gradient. The efficiency of Carnot cycle is given by

$$
\eta_{c}=1-\frac{T_{\text {low }}}{T_{\text {high }}} .
$$

We can see from the formula that Carnot efficiency is limited to small $\Delta T$ which is equal to $T_{\text {low }} / T_{\text {high }}$.

At present, the core contents of the thermoelectric technology research are concentrated on improving the thermoelectric properties of existing thermoelectric materials with in-depth study, researching of new thermoelectric materials, developing functionally graded thermoelectric materials, and reducing the number of dimensions of the thermoelectric materials in order to increase the output power under the conditions of the same thermal source. In recent years, a variety of techniques including physical vapor deposition (PVD), chemical vapor deposition (CVD), and electrochemical deposition (ECD) have been widely used in the development of thin-film thermoelectric materials which have outstanding qualities like the ability of combining with other microprocessing technologies and greatly improving the composition and structure of thermoelectric materials and thus increasing the thermoelectric figure of merit. However, due to a greater loss of contact resistance and thermal contact resistance, these devices have lower conversion efficiency now. The efficiency of the thermoelectric materials is simplified by assuming that the Seebeck coefficient, electrical conductivity, and thermal conductivity are independent of temperature for the exact expression of it is very complex and the formula is shown as follows [95]:

$$
\eta=\frac{\Delta T}{T_{\text {high }}} \times \frac{\sqrt{1+Z T}-1}{\sqrt{1+Z T}+T_{\text {low }} / T_{\text {high }}},
$$

where $Z T$ is thermoelectric figure of merit of materials. The actual efficiency of thermoelectric device is only about $90 \%$ of the above formula due to the loss of electrical interconnection, contact heat resistance, contact resistance, and other heat loss.

Francioso et al. developed a miniaturized TEG integrating an array of 100 thin- film thermocouples on flexible substrate with an area of about $70 \times 30 \mathrm{~mm}^{2}$, finalized to power very low consumption electronics Ambient Assisted Living applications [96]. A maximum open circuit output voltage of $430 \mathrm{mV}$ and an electrical output power up to $32 \mathrm{nW}$ was achieved with matched load at $\Delta T=40^{\circ} \mathrm{C}$. The TEG is flexible and wearable while it suffers from insufficient output voltage. It can be used for healthcare and biometric parameters monitoring and so forth.

Chen et al. presented a transparent micro-TEG ( $\mu$-TEG) fabricated by MEMS technology on a 4 -inch glass wafer [97]. A $60 \mathrm{~cm} \times 90 \mathrm{~cm}$ glass window assembled with the transparent $\mu$-TEG array can generate a power of $0.05 \sim 0.1 \mathrm{~W}$ under $5^{\circ} \mathrm{C} \sim$ $10^{\circ} \mathrm{C}$ temperature difference based on theoretical evaluation. This technology is compatible with IC manufacturing technology and has no requirement of sustained cooling. The $\mu$ TEG can be installed on the windows of the building for solar energy conversion applications.

The TEGs are characterized by small size, light weight, no vibration, no noise, safety and reliability, low maintenance cost, the ability of adapting to any special climate area, and working long hours in extreme environments [98]. In addition, it can take advantage of the so-called low-level thermal to generate power such as waste burning heat, geothermal, solar heat, and ocean heat; especially it is very promising in the application of generating power from industrial waste heat and exhaust heat [91]. Thus we can make full use of energy and reduce energy consumption and environmental pollution. Their usage is limited because of the low energy conversion efficiency and high costs. At present, the TEGs are mainly used in high-tech fields such as medical treatment, military, submarines, and cosmic space.

The efficiency of thermoelectric generators mainly depends upon thermoelectric materials performance, the number of thermocouples, and geometric crosssectional areas of thermocouple legs when in a certain application environment. So improving the performance of thermoelectric materials is a significant ongoing research to enhance the conversion efficiency and power density of thermoelectric generators. The main ongoing researches are designing and manufacturing various optimized microstructure thermoelectric devices using the MEMS micro machining means including optimizing length-area ratio of thermocouple legs and increasing thermocouple numbers per unit area to improve the output of thin-film thermopile, fabricating the thermocouple legs with large 
cross-sectional area to decrease the device resistance. The efficiency of thermoelectric generators decreases along with the reduction of thermocouple length due to contact impact, and the more appreciable the contact impact exists, the more rapid power harvesting efficiency reduces, so another ongoing research is reducing contact resistance and contact thermal resistance possibly of thermoelectric generators from the process point during the manufacture.

\section{Dynamic Fluid Energy Harvesting}

Dynamic fluid energy includes wind and flowing water power. The kinetic energy of fluid can be harvested by two methods. The first one generates electricity by mechanical parts such as micro turbine systems. The second one uses nonmechanical parts that works the same as the mechanical energy harvesting technology for the flowing wind or water induces mechanical vibration which can be converted to electricity by piezoelectric $[99,100]$, electrostatic [101], or electromagnetic principles [102]. The output mechanical power from the fluid energy harvesters is governed by the following equation:

$$
P_{m}=\frac{1}{2} C_{P} \rho A v^{3}
$$

where $C_{P}$ is the performance coefficient of the harvesters; in other words, it is the efficiency of flowing energy converted to mechanical energy and the theoretical maximum value is $16 / 27$ according to Batz theory, $\rho$ is the flow density in $\mathrm{kgm}^{-3}$, $A$ is the cross-sectional area in $\mathrm{m}^{2}$, and $v$ is the fluid velocity in $\mathrm{m} / \mathrm{s}$.

6.1. Micro Wind Harvester. The ambient air flow or forced convection [103] can also be an energy source for wireless autonomous sensor nodes in outdoor, remote, or inaccessible locations [104]. The existing methods of wind energy harvesting include micro wind turbines, micro windbelt generators, piezoelectric wind harvesters and electromagnetic wind generators. The conventional wind turbine is the most mature and commonly used method for harvesting wind energy, but the efficiency of it reduces with size due to the increased effect of friction losses in the bearings and the reduced surface area of the blades. In addition, the rotating components of conventional turbines, such as bearings, suffer from fatigue and wear [105]. The micro windbelt generator has a higher output power at high wind speeds $(>5.5 \mathrm{~m} / \mathrm{s})$, but its output power reduces significantly at low wind speeds $(<3.5 \mathrm{~m} / \mathrm{s})$, and the windbelt generator can be extremely noisy during operation [106]. The piezoelectric wind harvesters have some advantages including compact structure, sensitivity to low speed wind, higher efficiency, instant starting with no dead time, small size and ultralight weight, extremely low magnetic permeability, and almost no heat dissipation [107]. But the poor piezoelectric strain coefficient of existing materials may result in a very low output power, and the piezoelectric materials have a resonant frequency that the maximum power will be generated only when the piezoelectric materials vibrate at their resonant frequency. The electromagnetic wind

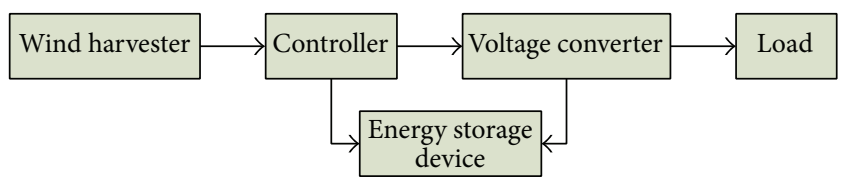

FIGURE 6: The composition block diagram of micro wind power system.

generators are reliable and have small mechanical damping, but the heavy magnet will result in the generator being not able to operate at low wind speed [108].

Generally, the composition block diagram of micro wind power system is shown as follows (Figure 6).

The controller is used to ensure the normal charge, discharge of the energy storage device, and controlling the tip speed ratio of the wind generator to make it working in the best power points so as to achieve the highest efficiency of the system [109].

Because the intermittence and instability of wind will lead to the problem of unstable power supply, the energy storage device is used to provide a stable and continuous power for wireless sensors to ensure the safe and sustained operation.

Carli et al. [110] developed a plastic four-bladed horizontal-axis wind turbine with an overall volume below $300 \mathrm{~cm}^{3}$. The experimental results in the given conditions showed a harvested continuously energy about $8 \mathrm{~mW}$ on average and an average power continuously available of about $7 \mathrm{~mW}$ with a buck-boost converter supposed efficiency of $85 \%$. The power generated in setting conditions is sufficient for low power sensor nodes, but the volume of the system is relatively large. The wind energy harvester introduced in this paper is suitable for powering small size embedded systems which are deployed in outdoor environment.

Priya demonstrated a piezoelectric windmill energy harvesting device consisting of 12 piezoelectric bimorph transducers which oscillate by turn to produce electricity as the wind flows through the windmill [51]. The circumference of the windmill is about $10 \mathrm{~mm}$. A power of $10.2 \mathrm{~mW}$ was successfully achieved. The generated power can be controlled by changing the number of bimorphs in the windmill, and it provides a solution to the remote and communication devices which require power in the range of $10-50 \mathrm{~mW}$, including sensors for weather monitoring and structural health monitoring, accelerometers, strain gages, thermal sensors, switches, and alarms. But this research still faces challenges associated with circuit of storing the electrical energy, complex design, and relatively large size.

Tan and Panda presented a piezoelectric wind harvester and utilized the bimorph piezoelectric actuator for a low power autonomous wind speed sensor [107]. When the storage capacitor charged to maximum voltage equaled to $917 \mathrm{uJ}$, a trigger signal was initiated to release the energy to the RF transmitter. The piezoelectric wind harvester together with its related electronics is smaller and lighter compared to other windmills, but the harvested energy is quite limited and the network cannot handle unexpected events for the duty 
cycle of sensor is too small. So it can be adopted in the WSNs with small amount of data and insensitive delay.

The wind energy is inexhaustible, renewable, free to use, nonpolluting, widely distributed in the country, and so forth. But it has low energy density, regional differences, and unstable factor for the wind speed is fluctuant and unpredictable which will result in producing inequable electricity all the time [111]. Moreover, the wind harvester can be noisy as it has moving mechanical part [44].

It is a key to make the wind turbine system work at the maximum power point due to the instability of wind. To further improve the efficiency of wind turbines, it is needed to research and develop efficient MPPT control technology according to the specific characteristics of wind energy. The design of MPPT control technology is difficult due to the big rotational inertia and relatively complex control of wind turbine. So the robust control research of maximum wind energy capture becomes a hot spot for the wind power system with nonlinearity and stochastic disturbance.

6.2. Flowing Water Energy Harvesting. The flowing water contains kinetic energy due to the water pressure fluctuation, and it can be converted into electrical energy by energy harvesters [112]. Flowing water is a renewable, pollution-free, continuous, and dependable energy source for wireless sensor nodes [113]. For hydropower can be developed in any size and any scale, it is applicable in WSNs [34].

Sun and $\mathrm{Hu}$ [114] developed an electromagnetic vibratory generator based on impact of water current. The experiment showed that the amount of generated power increases when the water current impacts at the center of coil box or the velocity and total volume of it increase and decreases with the water height at the bottom of generator increase and reaches the maximum at some impacting water volume per unity time. The proposed generator is relatively large to integrate with the small sensors. The generator can be fixed at outlets of fluidic transportation and storage facilities to convert water current energy into electrical energy for low-power systems.

Pobering and Schwesinger [113] presented two types of energy harvester, a flag-shaped piezoelectric polymer harvester and a microstructured piezobimorph generator, to convert the kinetic energy of flowing water into electrical energy. The first type is applied in turbulent flow as it can bend periodically for the different flow velocities on two sides resulting in different pressure to generate power. This generator is produced easily and cost effective with screen printing technologies, but the maximum power conversion efficiency is quite limited for the d31-coefficient of PVDF is very low. The second type is placed in an instable flow to produce an altering pressure on the PZT, and then power is generated. Mechanical theories show that the longer and thinner the beam is, the higher the energy generated is. A power of about $6.81 \mu \mathrm{W}$ can be achieved theoretically of the PZT-ceramic generator with a transfer factor of about $8 \%$, a volume of $100 \mathrm{~mm}^{3}$ and a flow velocity of $2 \mathrm{~m} / \mathrm{s}$. The low energy can be utilized by low-power sensors or the micro generator can work in parallel to form a micro power plant anchored in a flowing river to enhance the power rating. Unlike turbines or propellers, both converters have no rotating parts and need no maintenance.

The flowing water energy harvesting systems can be used to power the WSNs which are used with a growing interest to monitor the water quality and hydraulic state [115] of water distribution systems, river, and so forth. In applications, the type of energy harvesters is chosen based on the different requirements with size and amount of energy. The hydroturbine is able to generate enough power for wireless sensors, but it has a big size resulting in the difficulty of installing in pipelines and integrating with the sensor node. While the flow-induced vibration energy harvester has a micro size, it needs further research to increase the conversion efficiency and optimize the generated power to be appropriate for powering wireless sensor nodes [116].

\section{The Acoustic Energy}

The acoustic energy can be used by people like other forms of energy. When sound wave spreads to the surface of an object, it will cause vibration of the object. It was measured that the generated power is up to $100 \mathrm{~kW}$ when the noise of jet is $160 \mathrm{~dB}$. It can be seen that the power contained by acoustic energy is huge in the case of high decibel levels.

The available form of acoustic power spectra contains the longitudinal, transverse, bending, hydrostatic, or shears waves. The common elements of acoustic energy systems include an input mechanical power spectrum, an effective acoustic impedance matching, a piezoelectric or biased electrostrictive transducers converting the input mechanical energy into electrical energy and a matched electrical load [117].

Iizumi et al. [118] presented a micro electromechanical PZT acoustic energy harvester having dual top electrodes to utilize the different polarity charges in the central part and the peripheral part of a vibrating PZT diaphragm. The peripheral, central, and connected energy harvester generated powers of $5.28 \times 10^{-11} \mathrm{~W}, 4.25 \times 10^{-11} \mathrm{~W}$, and $8.28 \times 10^{-11} \mathrm{~W}$ under the sound pressure level of $100 \mathrm{~dB}$ at resonance frequency of $4.92 \mathrm{kHz}$, respectively. The power is nearly two times larger than that generated by the other devices with similar diaphragm. The harvester can be adopted in the applications with a very low amount of data and high noise; then the noise control and energy harvesting can be achieved simultaneously.

Liu et al. [119] proposed an electromechanical Helmholtz resonator (EMHR) as an acoustic energy harvester. This study adopted an extra flyback converter to compare with the single direct charging circuit and condition the generated energy. Experimental results showed that the output power is approximately $30 \mathrm{~mW}$ at $161 \mathrm{~dB}$ SPL with a flyback converter to alleviate the problem of load mismatch, which is much higher than the direct charging circuit. But except the electrical energy dissipated by the diodes, the plane wave tube controller of the flyback converter introduced an extra energy consumption and acoustic impedance mismatch which results in a rather low overall efficiency varied from $6 \%$ to $1.5 \%$ with acoustic input pressures between 145 and $161 \mathrm{~dB}$. 
The device can be used for low-power electronics and sensors placed in very high sound pressure level environment such as the engine nacelle.

The acoustic energy can be utilized to power the sensor nodes placed in a high sound pressure level environment such as the side of a engine nacelle for the acoustic energy has a very low power density which can be seen from Table 1. And acoustic energy harvesting will not only satisfy the power demand of wireless sensors, but also improve the environmental conditions by reducing the noise [120].

\section{Magnetic Energy Harvesting}

The magnetic energy, an inexhaustible and renewable power source, is ubiquitous on the earth. At present, the researches on harvesting magnetic field energy for wireless sensors are relatively few and mainly concentrate on specific aspects of power transmission/distribution lines. Recently, with the demand of a "Smart Grid" [121, 122], some parameters of assets and power lines need to be monitored in real time by wireless sensors like line temperature, line sag, icing, vibration, corrosion in steel core, broken strand, corona, audible noise [123], and so forth. According to the magnetic effect of electric current, a changed magnetic field is produced around the power lines since alternating current is transmitted. And we can utilize the produced magnetic field energy to provide power for wireless sensors. Although the power density of the magnetic field is not high, if properly used, it is enough to offer energy for low-power wireless sensor.

Tashiro et al. [32] utilized an energy harvesting module with an air-core coil and a resonant capacitor to harvest magnetic energy from power lines. The experiment proved that the voltage amplitude and quality factor increase with the increasing of the spacing factor and mean radius of the coil. However, it can also result in higher energy loss for the higher coil resistance and undesired eddy current loss in the coil. A highest power of $6.32 \mathrm{~mW}$ was achieved with the best harvesting module from a magnetic field of 21.2 at $60 \mathrm{~Hz}$. The harvested energy is feasible for the wireless sensors, but the energy harvesting modules are bulky compared to a sensor nodes and the uniform experimental magnetic field is too simplified compared to which in practice. Also, the pure iron rods chosen can cause large eddy current loss.

Moghe et al. [124] proposed two methods to harvest energy from magnetic field around a current carrying utility asset: a piezoelectric bimorph and a flux concentrator-core current transformer. The piezoelectric bimorph is able to provide an average power of $26.4 \mathrm{~mW}$ which is enough for a wireless senor. But its inability to provide power continuously results in the need of an energy storage. And in practice, there also exists the problem of how to clamp it around the conductor. While another method where a flux concentratorcore current transformer with very small surface area $(54 \times$ $64 \mathrm{~mm}^{2}$ ) can provide $257 \mathrm{~mW}$ when there was $1000 \mathrm{~A}$ in the transmission line. It has the advantage of small size and being able to stick to the conductor. But in practical application, the misalignment between core and conductor will cause a great reduction in the harvested energy. And also, the distance of the core from the conductor should be controlled for which is almost inversely proportional to the harvested energy.

At present, the study of harvesting magnetic field energy around power lines is still in its initial stage. There are some other researches like the study of Zhu et al. [122, 125], Guo et al. [126]; however, these all still have many problems more or less that need to be solved in practical application, for instance, how to install the generator around the conductor, reduce the size of the harvester, and eliminate the insulation problems such as corona and partial discharge. And also the influence of the operation environment must be considered, like weather condition, contamination, line sag and oscillation [126], and so forth.

\section{Hybrid Power Source}

The amount of energy from a single energy harvester is typically small [127] and highly variable with time, its location, and working conditions of load $[73,74]$, so the dependence on a single energy source may cause some potential problems for once the environment is in short supply of this energy, the node will not be able to work normally and reliably. And generally, there are many different forms of available energy source existing simultaneously in the environment. In order to make each sensor node obtain the required energy from environment as much as possible, we may need to design such a kind of energy harvesting system that it cannot only harvest energy from one type of power source [128]. Therefore, it is necessary to integrate a variety of energy harvesting modules in one sensor node [129]. And it is absolutely difficult which is mainly shown in the following areas.

(1) All kinds of energy harvesting technologies are still not mature and need the innovative research.

(2) We should guarantee that the various energy harvesting components can meet the demanding requirements of sensor nodes in size.

(3) It must be ensured that all kinds of energy harvesting components can work harmonically and store the harvested energy efficiently.

Professor Wang Zhong-lin and his team members of Georgia Institute of Technology developed a composite nanogenerator which can harvest solar energy and mechanical energy at the same time. It was the first time that people utilized a single integrated device to harvest different forms of energy simultaneously [130]. The generator was confirmed that the two parts of it can not only work together, but also operate independently without interplay. They also found that the output voltage of the solar cell can greatly enhance that of the nanogenerator and the output current, voltage, and power of the generator improved greatly through the series and parallel design. This invention showed that it is feasible to harvest different forms of energy by an integrated generator and this study also explored a new research field which takes advantages of a variety of different energy with a high efficiency.

Yu et al. designed a photovoltaic and thermoelectric hybrid energy harvester for WSNs by attaching TEGs to the 
TABLE 8: The comparison of various energy harvesting methods for WSNs.

\begin{tabular}{|c|c|c|c|}
\hline Energy sources & $\begin{array}{l}\text { Voltage } \\
\text { regulation }\end{array}$ & $\begin{array}{l}\text { Energy } \\
\text { storage } \\
\text { device } \\
\text { needed }\end{array}$ & The possible applications in WSNs \\
\hline Photovoltaics & Maybe & Usually & $\begin{array}{l}\text { Sensors in outdoors or in where with long time artificial } \\
\text { light like the shopping centers, factories, and so forth }\end{array}$ \\
\hline \multicolumn{4}{|c|}{ Mechanical energy harvesters } \\
\hline $\begin{array}{l}\text { Piezoelectric } \\
\text { Electrostatic } \\
\text { Electromagnetic }\end{array}$ & Yes & Usually & $\begin{array}{c}\text { Sensors installed on (or in contact with) moving or } \\
\text { working bodies, vehicles, engines, or other vibration or } \\
\text { mechanical sources }\end{array}$ \\
\hline TEG & Maybe & Usually & $\begin{array}{l}\text { Sensors in where existing temperature differs with } \\
\text { surroundings like body surface, engine, and so forth }\end{array}$ \\
\hline \multicolumn{4}{|l|}{ Dynamic fluid energy } \\
\hline Wind harvester & Yes & Yes & Sensors in outdoors or in moving or rotating objects \\
\hline Flowing water & Yes & Usually & $\begin{array}{l}\text { Sensors in the water or with direct contact of water or } \\
\text { with automated watering }\end{array}$ \\
\hline Acoustic energy & Yes & Yes & $\begin{array}{l}\text { Sensors where high level noise exists such as shopping } \\
\text { centers, factories, and so forth; the side of objects with } \\
\text { high-decibel like engine nacelles }\end{array}$ \\
\hline Magnetic field energy & Yes & Usually & $\begin{array}{c}\text { Sensors where existing strong magnetic field exists such } \\
\text { as power transmission/distribution lines }\end{array}$ \\
\hline
\end{tabular}

rear of a $150 \mathrm{~mm} \times 80 \mathrm{~mm}$ solar cell to absorb the heat energy [131]. Results show that the open circuit voltage and conversion efficiency of the solar cell increased by $0.3 \mathrm{~V}$ and $5.2 \%$, respectively, and the rear temperature was $13^{\circ} \mathrm{C}$ lower compared to the single solar cell when the solar irradiance and the ambient temperature were $778 \mathrm{~W} / \mathrm{m} 2$ and $32^{\circ} \mathrm{C}$, respectively. However, the harvester is bulk compared to the small sensor.

Wischke et al. developed a double-side suspended hybrid energy harvester with a piezoelectric and an electromagnetic transducer merged to increase the power output [132]. At resonance $300 \mu \mathrm{W}$ and $120 \mu \mathrm{W}$ can be drawn from the piezoelectric and electromagnetic generator parts, respectively, with $10 \mathrm{~m} / \mathrm{s}^{2}$ sinusoidal excitation and optimal load conditions. The harvester is characterized by novel structure, low-cost fabrication, and modular setup, and the moving magnet configuration maximizes the seismic mass and avoids the problem of attaching electrical contacts to the inductor. The power output can be enhanced by increasing the seismic mass with the resonance frequency decreased, but the system volume is also increased. And the manual assembly and aligning of the inductors and magnets raise problems such as misalignment and low manufacturability. It can be used in many vibration-based applications by further reducing the resonance frequency.

\section{Conclusion}

WSNs have provided attractive solutions for a variety of applications, but the sensor nodes energy supply is one of the important issues needed to be solved now. The environmental energy harvesting technologies are likely to replace the batteries in the future to realize the independent power supply of the wireless sensor nodes. In addition, there are some other advantages to employ energy harvesting technology such as noise reduction, elimination of cross-talks, and all these power sources are renewable, clean, and available limitlessly in the environment. This paper gives a comprehensive introduction of the various possible environmental energy harvesting technologies and the selection of which should be suitable for the actual applications and working environments of WSNs. Table 8 gives a brief summary of all the energy harvesting methods and the possible applications in WSNs.

At present, the environmental energy harvesting technologies still have many defects; for instance, the output power and conversion efficiency are low, environmental energy may not stable, the device cannot operate when there is not enough ambient energy, and the price of micropower generators is relatively high compared to batteries [133]. The development tendency of environmental energy harvesting technology includes the following aspects.

(1) As mentioned above, there are a lot of different forms of energy in the environment. And in order to enable each sensor node to obtain the required energy on long term and steadily from the environment, we may need to integrate a variety of energy harvesting technologies with the same sensor node and ensure that all kinds of energy harvesting technologies can work coordinately and store energy effectively.

(2) Up to now, there is a great distance between the existing energy harvesting technologies and the mass commercial production for all kinds of environmental energy harvesting technologies are still not mature, and the output power and energy conversion efficiency are low, so the coupling characteristics between the various energy and harvested power, and the 
related parameters of energy harvesting structure need to be further optimized.

(3) The size of energy harvesting system should be reduced as much as possible for the strict requirements of sensor nodes in many applications. Miniaturization is the development tendency of the future energy harvesting system.

(4) It is essential to combine the structure design and key circuits with the scheduling and agreement based on power-aware of wireless sensor nodes to prolong the sensor nodes life.

(5) It is a necessity to integrate the energy harvesting method, power management strategy, battery recharging, and new communication standards with sensor nodes in order to achieve the ultimate goal of permanent use of wireless sensors and broadening the market application.

\section{Conflict of Interests}

The authors declare that they do not have any commercial or associative interest that represents a conflict of interests in connection with this work.

\section{Acknowledgments}

The material presented in this paper is based upon work supported by the National Natural Science Foundation of China (no. 61104211), by Jiangsu Provincial Natural Science Foundation of China (no. BK2011214), by Research Fund for the Doctoral Program of Higher Education of China (no. 20110095120005), by China Postdoctoral Science Foundation (no. 20110491490), and by the Priority Academic Program Development of Jiangsu Higher Education Institutions.

\section{References}

[1] K. A. Kumar, "IMCC protocol in heterogeneous wireless sensor network for high quality data transmission in military applications," in Proceedings of the 1st International Conference on Parallel, Distributed and Grid Computing (PDGC '10), pp. 339343, October 2010.

[2] F. T. Jaigirdar, M. M. Islam, and S. R. Huq, "An efficient and cost effective maximum clique analysis based approximation in military application of wireless sensor network," in Proceedings of the 14th International Conference on Computer and Information Technology (ICCIT '11), pp. 85-90, December 2011.

[3] P. Padhy, K. Martinez, A. Riddoch, J. Hart, and H. Ong, "Glacial environment monitoring using sensor networks," in Proceedings of the Conference on Real-World Wireless Sensor Networks, 2005.

[4] J. A. Stankovic, Q. Cao, T. Doan et al., "Wireless sensor networks for in-home healthcare: potential and challenges," in Proceedings of the the High Confidence Medical Device Software Systems Workshop, 2005.

[5] G. Virone, A. Wood, L. Selavo et al., "An assisted living oriented information system based on a residential wireless sensor network," in Proceedings of the 1st Transdisciplinary Conference on Distributed Diagnosis and Home Healthcare (D2H2 '0606), pp. 95-100, April 2006.
[6] B. Płaczek, "Selective data collection in vehicular networks for traffic control applications," Transportation Research Part C: Emerging Technologies, vol. 23, pp. 14-28, 2012.

[7] M. R. Akhondi, A. Talevski, S. Carlsen, and S. Petersen, "Applications of wireless sensor networks in the oil, gas and resources industries," in Proceedings of the 24th IEEE International Conference on Advanced Information Networking and Applications (AINA '10), pp. 941-948, April 2010.

[8] N. Hubbell and Q. Han, "DRAGON: detection and tracking of dynamic amorphous events in wireless sensor networks," IEEE Transactions on Parallel and Distributed Systems, vol. 23, no. 7, pp. 1193-1204, 2012.

[9] A. Elancheziyan, J. C. De Oliveira, and S. Weber, "A new system for controlled testing of sensor network applications: architecture, prototype and experimental evaluation," Ad Hoc Networks, vol. 10, no. 6, pp. 1101-1114, 2012.

[10] J. Yick, B. Mukherjee, and D. Ghosal, "Wireless sensor network survey," Computer Networks, vol. 52, no. 12, pp. 2292-2330, 2008.

[11] Y.-T. Yong, C.-O. Chow, J. Kanesan, and H. Ishii, "A survey on design of self-powered wireless sensor network," in Proceedings of the International Conference for Technical Postgraduates (TECHPOS '09), pp. 1-5, December 2009.

[12] A. B. Nacef, S.-M. Senouci, Y. Ghamri-Doudane, and A.-L. Beylot, "A cooperative low power Mac protocol for wireless sensor networks," in Proceedings of the IEEE International Conference on Communications (ICC '11), pp. 1-6, June 2011.

[13] S. Dash, A. R. Swain, and A. Ajay, "Reliable energy aware multitoken based MAC protocol for WSN," in Proceedings of the 26th IEEE International Conference on Advanced Information Networking and Applications (AINA '12), pp. 144-151, March 2012.

[14] G.-G. Mplemenos and I. Papaefstathiou, "Fast and powerefficient hardware implementation of a routing scheme for WSNs," in Proceedings of the IEEE Wireless Communications and Networking Conference (WCNC '12), pp. 1710-1714, April 2012.

[15] L. Tao and L. Feng, "Power-efficient clustering routing protocol based on applications in wireless sensor network," in Proceedings of the 5th International Conference on Wireless Communications, Networking and Mobile Computing (WiCOM '09), pp. 1-6, September 2009.

[16] R. Bhuvaneswari and B. J. Bejoy, "Energy efficient reliable transport protocol for re-tasking in wireless sensor network," in Proceedings of the National Conference on Innovations in Emerging Technology (NCOIET '11), pp. 1-6, February 2011.

[17] H.-Y. Zhou, F. Wu, and K.-M. Hou, "An event-driven multithreading real-time operating system dedicated to wireless sensor networks," in Proceedings of the International Conference on Embedded Software and Systems (ICESS '08), pp. 3-12, July 2008.

[18] S. Roundy, P. K. Wright, and J. Rabaey, "A study of low level vibrations as a power source for wireless sensor nodes," Computer Communications, vol. 26, no. 11, pp. 1131-1144, 2003.

[19] V. Raghunathan, S. Ganeriwal, and M. Srivastava, "Emerging techniques for long lived wireless sensor networks," IEEE Communications Magazine, vol. 44, no. 4, pp. 108-114, 2006.

[20] J. Wu and G. Zhou, "A new ultra-low power wireless sensor network with integrated energy harvesting, data sensing, and wireless communication," in Proceedings of the IEEE International Conference on Communications (ICC '11), pp. 1-5, 2011.

[21] R. J. M. Vullers, R. van Schaijk, I. Doms, C. Van Hoof, and R. Mertens, "Micropower energy harvesting," Solid-State Electronics, vol. 53, no. 7, pp. 684-693, 2009. 
[22] T. V. Prabhakar, S. Devasenapathy, H. S. Jamadagni, and R. V. Prasad, "Smart applications for energy harvested WSNs," in Proceedings of the 2nd International Conference on Communication Systems and Networks (COMSNETS '10), pp. 1-7, January 2010.

[23] C. Alippi and C. Galperti, "An adaptive system for opimal solar energy harvesting in wireless sensor network nodes," IEEE Transactions on Circuits and Systems I: Regular Papers, vol. 55, no. 6, pp. 1742-1750, 2008.

[24] S. W. Arms, C. P. Townsend, D. L. Churchill et al., "Energy harvesting, wireless, structural health monitoring and reporting system," Materials Forum, vol. 33, pp. 220-234, 2008.

[25] N. S. Shenck and J. A. Paradiso, "Energy scavenging with shoemounted piezoelectrics," IEEE Micro, vol. 21, no. 3, pp. 30-42, 2001.

[26] G.-J. Sheu, S.-M. Yang, and T. Lee, "Development of a low frequency electrostatic comb-drive energy harvester compatible to SoC design by CMOS process," Sensors and Actuators, A: Physical, vol. 167, no. 1, pp. 70-76, 2011.

[27] Ö. Zorlu, E. T. Topal, and H. Külah, "A vibration-based electromagnetic energy harvester using mechanical frequency up-conversion method," IEEE Sensors Journal, vol. 11, no. 2, pp. 481-488, 2011.

[28] Ö. Zorlu, E. T. Topal, and H. Külah, "An electromagnetic micro power generator for low-frequency environmental vibrations based on the frequency up conversion technique," IEEE Journal of Microelectromechanical Systems, vol. 11, no. 2, pp. 481-488, 2011.

[29] S. P. Beeby, R. N. Torah, M. J. Tudor et al., "A micro electromagnetic generator for vibration energy harvesting," Journal of Micromechanics and Microengineering, vol. 17, no. 7, article 007, pp. 1257-1265, 2007.

[30] D. Pescovitz, 2002, The Power of Small Tech. Smalltimes. 2, 1.

[31] D. Vatansever, R. L. Hadimani, T. Shah, and E. Siores, "An investigation of energy harvesting from renewable sources with PVDF and PZT," Smart Materials and Structures, vol. 20, no. 5, Article ID 055019, 2011.

[32] K. Tashiro, H. Wakiwaka, S.-I. Inoue, and Y. Uchiyama, "Energy harvesting of magnetic power-line noise," IEEE Transactions on Magnetics, vol. 47, no. 10, pp. 4441-4444, 2011.

[33] J. M. Gilbert and F. Balouchi, "Comparison of energy harvesting systems for wireless sensor networks," International Journal of Automation and Computing, vol. 5, no. 4, pp. 334-347, 2008.

[34] S. R. K. Tabbakh, R. Maarefdoust, N. C. Kyun, and B. Mohd Ali, "Environmental taxonomy of power scavenging techniques for autonomous self powered wireless sensors," in Proceedings of the Asia Pacific Conference on Circuit and System (APCCAS '10), pp. 1031-1034, December 2010.

[35] S. Roundy, D. Steingart, L. Frechette, P. Wright, and J. Rabaey, Power Sources for Wireless Sensor Networks, Lecture Notes in Computer Science, Springer, 2004.

[36] D. Brunelli, L. Benini, C. Moser, and L. Thiele, "An efficient solar energy harvester for wireless sensor nodes," in Proceedings of the Design, Automation and Test in Europe (DATE '08), pp. 104-109, March 2008.

[37] J. Gakkestad and L. Hanssen, "Powering wireless sensor networks nodes in Northern Europe using solar cell panel for energy harvesting," in Proceedings of the 4th IFIP International Conference on New Technologies, Mobility and Security (NTMS '11), pp. 1-5, February 2011.

[38] V. Raghunathan, A. Kansal, J. Hsu, J. Friedman, and M. Srivastava, "Design considerations for solar energy harvesting wireless embedded systems," in Proceedings of the 4th International Symposium on Information Processing in Sensor Networks (IPSN '05), pp. 457-462, April 2005.

[39] P. T. V. Bhuvaneswari, R. Balakumar, V. Vaidehi, and P. Balamuralidhar, "Solar energy harvesting for wireless sensor networks," in Proceedings of the 1st International Conference on Computational Intelligence, Communication Systems and Networks (CICSYN '09), pp. 57-61, July 2009.

[40] M. Barnes, C. Conway, J. Mathews, and D. K. Arvind, "ENS: an energy harvesting wireless sensor network platform," in Proceedings of the 5th International Conference on Systems and Networks Communications (ICSNC '10), pp. 83-87, August 2010.

[41] S. Chalasani and J. M. Conrad, "A survey of energy harvesting sources for embedded systems," in Proceedings of IEEE Southeastcon, pp. 442-447, April 2008.

[42] M. K. Stojcev, M. R. Kosanovic, and L. R. Golubovic, "Power management and energy harvesting techniques for wireless sensor nodes," in Proceedings of the 9th International Conference on Telecommunication in Modern Satellite, Cable, and Broadcasting Services (TELSIKS '09), pp. 65-72, 2009.

[43] R. Morais, S. G. Matos, M. A. Fernandes et al., "Sun, wind and water flow as energy supply for small stationary data acquisition platforms," Computers and Electronics in Agriculture, vol. 64, no. 2, pp. 120-132, 2008.

[44] Z. G. Wan, Y. K. Tan, and C. Yuen, "Review on energy harvesting and energy management for sustainable wireless sensor networks," in Proceedings of the IEEE 13th International Conference on Communication Technology (ICCT '11), pp. 362367, September 2011.

[45] Z. Hadas, V. Singule, S. Vechet, and C. Ondrusek, "Development of energy harvesting sources for remote applications as mechatronic systems," in Proceedings of the 14th International Power Electronics and Motion Control Conference (EPE-PEMC '10), pp. T1013-T1019, September 2010.

[46] Solarzoom, 2012, Japanese developed a spherical solar cells with efficiency far more than the flat-panel. 6 .

[47] China Education and Research Network, "Canadian scientists developed a kind of full spectrum solar cell," 2011, http://www.edu.cn/.

[48] Solar. Ofweek, "American researchers found the more absorbent ultra-thin film photovoltaic cells," 2012, http://solar .ofweek.com.

[49] Sciencenet, "Scientists invented solar cells with thick less than two microns which are thinner than spider web," 2012, http://news.sciencenet.cn.

[50] C. Ó. Mathúna, T. O’Donnell, R. V. Martinez-Catala, J. Rohan, and B. O'Flynn, "Energy scavenging for long-term deployable wireless sensor networks," Elsevier Talanta, vol. 75, pp. 613-623, 2008.

[51] S. Priya, "Advances in energy harvesting using low profile piezoelectric transducers," Journal of Electroceramics, vol. 19, no. 1, pp. 165-182, 2007.

[52] P. D. Mitcheson, E. M. Yeatman, G. K. Rao, A. S. Holmes, and T. C. Green, "Energy harvesting from human and machine motion for wireless electronic devices," Proceedings of the IEEE, vol. 96, no. 9, pp. 1457-1486, 2008.

[53] H. S. Kim, J.-H. Kim, and J. Kim, "A review of piezoelectric energy harvesting based on vibration," International Journal of Precision Engineering and Manufacturing, vol. 12, no. 6, pp.11291141, 2011. 
[54] J. Chang and L. Lin, "Large array electrospun PVDF nanogenerators on a flexible substrate," in Proceedings of the 16th International Solid-State Sensors, Actuators and Microsystems Conference (TRANSDUCERS '11), pp. 747-750, June 2011.

[55] Y. C. Shu, "Performance evaluation of vibration-based piezoelectric energy scavengers," in Energy Harvesting Technologies, chapter 3, pp. 79-105, 2009.

[56] S. Saadon and O. Sidek, "Vibration-based MEMS piezoelectric energy harvester (VMPEH) modeling and analysis for green energy source," in Proceedings of the 4th International Conference on Developments in eSystems Engineering (DeSE '11), pp. 527-531, December 2011.

[57] S. Saadon and O. Sidek, "A review of vibration-based MEMS piezoelectric energy harvesters," Energy Conversion and Management, vol. 52, no. 1, pp. 500-504, 2011.

[58] F. Lu, H. P. Lee, and S. P. Lim, "Modeling and analysis of micro piezoelectric power generators for micro-electromechanicalsystems applications," Smart Materials and Structures, vol. 13, no. 1, pp. 57-63, 2004.

[59] M. A. Karami, O. Bilgen, D. J. Inman, and M. I. Friswell, "Experimental and analytical parametric study of single-crystal unimorph beams for vibration energy harvesting," IEEE Transactions on Ultrasonics, Ferroelectrics, and Frequency Control, vol. 58, no. 7, pp. 1508-1520, 2011.

[60] A. Erturk, W. G. R. Vieira, C. De Marqui Jr., and D. J. Inman, "On the energy harvesting potential of piezoaeroelastic systems," Applied Physics Letters, vol. 96, no. 18, article 184103, 2010.

[61] J. Palosaari, M. Leinonen, J. Hannu, J. Juuti, and H. Jantunen, "Energy harvesting with a cymbal type piezoelectric transducer from low frequency compression," Journal of Electroceramics, vol. 28, no. 4, pp. 214-219, 2012.

[62] X. Li, M. Guo, and S. Dong, "A flex-compressive-mode piezoelectric transducer for mechanical vibration/strain energy harvesting," IEEE Transactions on Ultrasonics, Ferroelectrics, and Frequency Control, vol. 58, no. 4, pp. 698-703, 2011.

[63] A. Erturk and D. J. Inman, "An experimentally validated bimorph cantilever model for piezoelectric energy harvesting from base excitations," Iopscience Smart Materials and Structures, vol. 18, no. 2, 2009.

[64] A. Khaligh, P. Zeng, and C. Zheng, "Kinetic energy harvesting using piezoelectric and electromagnetic technologiesstate of the art," IEEE Transactions on Industrial Electronics, vol. 57, no. 3, pp. 850-860, 2010.

[65] L. Mateu and F. Moll, "Optimum piezoelectric bending beam structures for energy harvesting using shoe inserts," Journal of Intelligent Material Systems and Structures, vol. 16, no. 10, pp. 835-845, 2005.

[66] S. B. Ayed, F. Najar, and A. Abdelkefi, "Shape improvement for piezoelectric energy harvesting applications," in Proceedings of the 3rd International Conference on Signals, Circuits and Systems (SCS '09), pp. 1-6, November 2009.

[67] J. Baker, S. Roundy, and P. Wright, "Alternative geometries for increasing power density in vibration energy scavenging for wireless sensor networks," in Proceedings of the 3rd International Energy Conversion Engineering Conference, pp. 959-970, August 2005.

[68] X.-R. Chen, T.-Q. Yang, W. Wang, and X. Yao, "Vibration energy harvesting with a clamped piezoelectric circular diaphragm," Ceramics International, vol. 38, no. 1, pp. S271-S274, 2012.

[69] C. Chang, V. H. Tran, J. Wang, Y.-K. Fuh, and L. Lin, "Directwrite piezoelectric polymeric nanogenerator with high energy conversion efficiency," Nano Letters, vol. 10, no. 2, pp. 726-731, 2010.

[70] X. Wang, "Piezoelectric nanogenerators-Harvesting ambient mechanical energy at the nanometer scale," Nano Energy, vol. 1, no. 1, pp. 13-24, 2012.

[71] G. D. Pasquale, E. Brusa, and A. Somà, "Capacitive vibration energy harvesting with resonance tuning," in Proceeding of Symposium on Design, Test, Integration \& Packaging of MEMS/MOEMS, pp. 280-285, 2009.

[72] T. Suzuki, S. Nagasawa, H. Okamoto, and H. Kuwano, "Novel vibration-driven micro-electrostatic induction energy harvester with asymmetric multi-resonant spring," in Proceedings of the 9th IEEE Sensors Conference (SENSORS '10), pp. 1161-1164, November 2010.

[73] L. Li, Y. Zhang, H. San, Y. I. Guo, and X. Chen, "MEMS for vibration energy harvesting," in MEMS/MOEMS Technologies and Applications III, vol. 6836 of Proceedings of the SPIE, 2008.

[74] Y. Li, H. Yu, B. Su, and Y. Shang, "Hybrid micropower source for wireless sensor network," IEEE Sensors Journal, vol. 8, no. 6, pp. 678-681, 2008.

[75] G. D. Pasquale and A. Somà, "Investigations on energy scavenging methods using MEMS devices," in Proceedings of the International Semiconductor Conference (CAS '08), vol. 1, pp. 163-166, 2008.

[76] O. Sidek, M. A. Khalid, M. Z. Ishak, and M. A. Miskam, “Design and simulation of SOI-MEMS electrostatic vibration energy harvester for micro power generation," in Proceedings of the 1st International Conference on Electrical, Control and Computer Engineering (InECCE '11), pp. 207-212, June 2011.

[77] G. Altena, D. Hohlfeld, R. Elfrink, M. H. Goedbloed, and R. Van Schaijk, "Design, modeling, fabrication and characterization of an electret-based MEMS electrostatic energy harvester," in Proceedings of the 16th International Solid-State Sensors, Actuators and Microsystems Conference (TRANSDUCERS '11), pp. 739-742, June 2011.

[78] E. Halvorsen, E. R. Westby, and S. Husa, "An electrostatic energy harvester with electret bias. Inof the TRANSDUCERS," in Proceedings of the International Solid-State Sensors, Actuators and Microsystems Conference, pp. 1381-1384, 2009.

[79] R. Mialtu and M. Sararoiu, "Electret based capacitive MEMS vibration-to-electric energy harvesting," in Proceedings of the International Semiconductor Conference (CAS '09), pp. 219-222, October 2009.

[80] M. R. B. Ahmad and M. H. B. M. Khir, "Design, analysis and fabrication of Electret-based micro-electromechanical systems energy harvester," in Proceedings of the National Postgraduate Conference (NPC '11), pp. 1-4, September 2011.

[81] S. Boisseau, G. Despesse, T. Ricart, E. Defay, and A. Sylvestre, "Cantilever-based electret energy harvesters," Smart Materials and Structures, vol. 20, no. 10, article 105013, 2011.

[82] K. Fujii, T. Toyonaga, T. Fujita, Y. G. Jiang, K. Higuchi, and K. Maenaka, "Electret based energy harvester using a shared si electrode," in Proceedings of the 16th International Solid-State Sensors, Actuators and Microsystems Conference (TRANSDUCERS '11), pp. 2634-2637, June 2011.

[83] Y. Wada, Y. Hamate, S. Nagasawa, and H. Kuwano, "Aging characteristics of electret used in a vibration-based electrostatic induction energy harvester," in Proceedings of the 16th International Solid-State Sensors, Actuators and Microsystems Conference (TRANSDUCERS '11), pp. 2626-2629, June 2011.

[84] S. Miki, T. Fujita, T. Kotoge et al., "Electromagnetic energy harvester by using buried NdFeB," in Proceedings of the IEEE 
25th International Conference on Micro Electro Mechanical Systems (MEMS '12), pp. 1221-1224, February 2012.

[85] Q. Yuan, X. Sun, D.-M. Fang, and H. Zhang, "Design and microfabrication of integrated magnetic MEMS energy harvester for low frequency application," in Proceedings of the 16th International Solid-State Sensors, Actuators and Microsystems Conference (TRANSDUCERS '11), pp. 1855-1858, June 2011.

[86] A. Rahimi, Ö. Zorlu, A. Muhtaroglu, and H. Külah, "A vibration-based electromagnetic energy harvester system with highly efficient interface electronics," in Proceedings of the 16th International Solid-State Sensors, Actuators and Microsystems Conference (TRANSDUCERS '11), pp. 2650-2653, 2011.

[87] K. Tao, G. Ding, P. Wang, Z. Yang, and Y. Wang, "Fully integrated micro electromagnetic vibration energy harvesters with micro-patterning of bonded magnets," in Proceedings of the IEEE 25th International Conference on Micro Electro Mechanical Systems (MEMS '12), pp. 1237-1240, February 2012.

[88] G. Despesse, T. Jager, C. Condemine, and P.-D. Berger, "Mechanical vibrations energy harvesting and power management," in Proceedings of the IEEE Sensors (SENSORS '08), pp. 29-32, October 2009.

[89] T. A. Carstens, M. L. Corradini, J. P. Blanchard, and Z. $\mathrm{Ma}$, "Thermoelectric powered wireless sensors for spent fuel monitoring," IEEE Transactions on Nuclear Science, vol. 59, no. 4, pp. 1408-1413, 2012.

[90] C. D. Stokes, A. Duff, M. J. Mantini, B. A. Grant, and R. Venkatasubramanian, "Nanostructured thermoelectric material and device technology for energy harvesting applications," in Proceedings of the 4th IEEE Nanotechnology Materials and Devices Conference (NMDC '10), pp. 154-159, October 2010.

[91] J. Smoker, M. Nouh, O. Aldraihem, and A. Baz, "Energy harvesting from a standing wave thermoacoustic-piezoelectric resonator," Journal of Applied Physics, vol. 111, no. 10, article 104901, 2012.

[92] D.-A. Borca-Tasciuc, M. M. Hella, and A. Kempitiya, "Micropower generators for ambient intelligence applications," in Proceedings of the 4th International Workshop on Soft Computing Applications (SOFA '10), pp. 19-24, July 2010.

[93] L. Mateu, C. Codrea, N. Lucas, M. Pollak, and P. Spies, "Human body energy harvesting thermogenerator for sensing applications," in Proceedings of the International Conference on Sensor Technologies and Applications (SENSORCOMM '07), pp. 366-372, October 2007.

[94] C. Lu, S. P. Park, V. Raghunathan, and K. Roy, "Analysis and design of ultra low power thermoelectric energy harvesting systems," in Proceedings of the ACM/IEEE International Symposium on Low-Power Electronics and Design (ISLPED '10), pp. 183-188, 2010.

[95] R. Vullers, R. Schaijk, H. Visser, J. Penders, and C. Hoof, "Energy harvesting for autonomous wireless sensor networks," IEEE Solid-State Circuits Magazine, vol. 2, no. 2, pp. 29-38, 2010.

[96] L. Francioso, C. De Pascali, I. Farella et al., "Flexible thermoelectric generator for wearable biometric sensors," in Proceedings of the 9th IEEE Sensors Conference (SENSORS '10), pp. 747-750, November 2010.

[97] G.-M. Chen, L.-Y. Ma, I.-Y. Huang, and T.-E. Wu, "Development of a novel transparent micro-thermoelectric generator for solar energy conversion," in Proceedings of the 6th IEEE International Conference on Nano/Micro Engineered and Molecular Systems (NEMS '11), pp. 976-979, February 2011.

[98] K. Miyazaki, M. Takashiri, J.-I. Kurosaki, B. Lenoir, A. Dauscher, and H. Tsukamoto, "Development of a micro-generator based on Bi2Te3 thin films," in Proceedings of the 26th International Conference on Thermoelectrics (ICT '07), pp. 294-299, June 2007.

[99] D.-A. Wang and H.-H. Ko, "Piezoelectric energy harvesting from flow-induced vibration," Journal of Micromechanics and Microengineering, vol. 20, no. 2, Article ID 025019, 2010.

[100] S. Pobering and N. Schwesinger, "Power supply for wireless sensor systems," in Proceedings of the IEEE Sensors Conference (SENSORS '08), pp. 685-688, October 2009.

[101] L. Bu, X. M. Wu, X. H. Wang, and L. T. Liu, "Liquidencapsulated energy harvester for low frequency vibrations," in Proceedings of the 16th International Solid-State Sensors, Actuators and Microsystems Conference (TRANSDUCERS '11), pp. 1673-1676, June 2011.

[102] D.-A. Wang and K.-H. Chang, "Electromagnetic energy harvesting from flow induced vibration," Microelectronics Journal, vol. 41, no. 6, pp. 356-364, 2010.

[103] L. G. Fréchette, "Micro energy conversion devices," in Encyclopedia of Microfluidics and Nanofluidics, D. Li, Ed., part 13, pp. 1119-1127, Springer Press, 2008.

[104] R. Myers, M. Vickers, H. Kim, and S. Priya, "Small scale windmill," Applied Physics Letters, vol. 90, no. 5, article 054106, 2007.

[105] X. Gao, W.-H. Shih, and W. Y. Shih, "Flow energy harvesting using piezoelectric cantilevers with cylindrical extension," IEEE Transactions on Industrial Electronics, vol. 60, no. 3, pp. 11161118, 2013.

[106] D. Zhu, S. Beeby, J. Tudor, N. White, and N. Harris, "A novel miniature wind generator for wireless sensing applications," in Proceedings of the 9th IEEE Sensors Conference (SENSORS '10), pp. 1415-1418, November 2010.

[107] Y. K. Tan and S. K. Panda, "A novel piezoelectric based wind energy harvester for low-power autonomous wind speed sensor," in Proceedings of the 33rd Annual Conference of the IEEE Industrial Electronics Society (IECON '07), pp. 2175-2180, November 2007.

[108] D. Ramasur and G. P. Hancke, "A wind energy harvester for low power wireless sensor networks," in Proceedings of the IEEE International Instrumentation and Measurement Technology Conference (I2MTC '12), pp. 2623-2627, May 2012.

[109] M. A. Weimer, T. S. Paing, and R. A. Zane, "Remote area wind energy harvesting for low-power autonomous sensors," in Proceedings of the 37th IEEE Power Electronics Specialists Conference (PESC '06), pp. 1-5, June 2006.

[110] D. Carli, D. Brunelli, D. Bertozzi, and L. Benini, "A highefficiency wind-flow energy harvester using micro turbine," in Proceedings of the International Symposium on Power Electronics, Electrical Drives, Automation and Motion (SPEEDAM '10), pp. 778-783, June 2010.

[111] A. Ucar and F. Balo, "Investigation of wind characteristics and assessment of wind-generation potentiality in Uludağ-Bursa, Turkey," Applied Energy, vol. 86, no. 3, pp. 333-339, 2009.

[112] D.-A. Wang and N.-Z. Liu, "A shear mode piezoelectric energy harvester based on a pressurized water flow," Sensors and Actuators, A: Physical, vol. 167, no. 2, pp. 449-458, 2011.

[113] S. Pobering and N. Schwesinger, "A novel hydropower harvesting device," in Proceedings of the International Conference on MEMS, NANO and Smart Systems (ICMENS '04), pp. 480-485, August 2004.

[114] J. Sun and J.-H. Hu, "Experimental study on a vibratory generator based on impact of water current," in Proceedings of the Symposium on Piezoelectricity, Acoustic Waves, and Device Applications (SPAWDA '11), pp. 40-43, December 2011. 
[115] G. Ye and K. Soga, "Energy harvesting from water distribution systems," Journal of Energy Engineering, vol. 138, no. 1, pp. 7-17, 2012.

[116] M. I. Mohamed, W. Y. Wu, and M. Moniri, "Power harvesting for smart sensor networks in monitoring water distribution system," in Proceedings of the International Conference on Networking, Sensing and Control (ICNSC '11), pp. 393-398, April 2011.

[117] S. Sherrit, "The Physical acoustics of energy harvesting," in Proceedings of the IEEE International Ultrasonics Symposium (IUS '08), pp. 1046-1055, November 2008.

[118] S. Iizumi, K. Shu, S. Tomioka et al., "Lead zirconate titanate acoustic energy harvesters utilizing different polarizations on diaphragm," in Proceedings of the 25th Eurosensors Conference, pp. 187-190, September 2011.

[119] F. Liu, A. Phipps, S. Horowitz et al., "Acoustic energy harvesting using an electromechanical Helmholtz resonator," Journal of the Acoustical Society of America, vol. 123, no. 4, pp. 1983-1990, 2008.

[120] N. Filip and I. Simu, "About the noise energy conversion from agriculture tractor engines," in Proceedings of the 39th International Symposium on Agricultural Engineering, pp. 29-37, 2011.

[121] S. Han, R. Hao, and J. Lee, "Inspection of insulators on highvoltage power transmission lines," IEEE Transactions on Power Delivery, vol. 24, no. 4, pp. 2319-2327, 2009.

[122] M. Zhu, P. C. Baker, N. M. Roscoe, M. D. Judd, and J. Fitch, "Alternative power sources for autonomous sensors in high voltage plant," in Proceedings of the IEEE Electrical Insulation Conference (EIC '09), pp. 36-40, June 2009.

[123] H. Zangl, T. Bretterklieber, and G. Brasseur, "A feasibility study on autonomous online condition monitoring of high-voltage overhead power lines," IEEE Transactions on Instrumentation and Measurement, vol. 58, no. 5, pp. 1789-1796, 2009.

[124] R. Moghe, Y. Yang, F. Lambert, and D. Divan, "A scoping study of electric and magnetic field energy harvesting for wireless sensor networks in power system applications," in Proceedings of the IEEE Energy Conversion Congress and Exposition (ECCE '09), pp. 3550-3557, September 2009.

[125] M. Zhu, M. D. Judd, and P. J. Moore, "Energy harvesting in substations for powering autonomous sensors," in Proceedings of the 3rd International Conference on Sensor Technologies and Applications (SENSORCOMM '09), pp. 246-251, June 2009.

[126] F. Guo, H. Hayt, and J. Wang, "Energy harvesting devices for high voltage transmission line monitoring," in Proceedings of the IEEE Power and Energy Society General Meeting, pp. 3550-3557, 2011.

[127] W. K. G. Seah, A. E. Zhi, and H.-P. Tan, "Wireless Sensor Networks Powered by Ambient Energy Harvesting (WSNHEAP) - survey and challenges," in Proceedings of the 1st International Conference on Wireless Communication, Vehicular Technology, Information Theory and Aerospace and Electronic Systems Technology, Wireless (VITAE '09), pp. 1-5, May 2009.

[128] Y. Shang, Y. Li, H. Yu, H. Sun, and B. Su, "Experimental investigation on thermoelectric generator of micro hybrid power source," in Proceedings of the 3rd International Symposium on Advanced Optical Manufacturing and Testing Technologies: Design, Manufacturing, and Testing of Micro- and Nano-Optical Devices and Systems, vol. 6724 of Proceedings of the SPIE, 2007.

[129] R. Silva, K. Farinholt, and G. Park, "Hybrid energy sources for embedded sensor nodes," in Proceedings of the Industrial and Commercial Applications of Smart Structures Technologies, March 2011.

[130] Sciencenet, "JACS: Wang Zhong-Lin group developed a compound nanometer generator," 2009, http://www.sciencenet.cn.

[131] H. Yu, Y. Li, Y. Shang, and B. Su, "Design and investigation of photovoltaic and thermoelectric hybrid power source for wireless sensor networks," in Proceedings of the 3rd IEEE International Conference on Nano/Micro Engineered and Molecular Systems (NEMS '08), pp. 196-201, January 2008.

[132] M. Wischke, M. Masur, and P. Woias, "A hybrid generator for virbration energy harvesting applications," in Proceedings of the 15th International Conference on Solid-State Sensors, Actuators and Microsystems (TRANSDUCERS '09), pp. 521-524, June 2009.

[133] B. Pekoslawski, P. Krasinski, and A. Napieralski, "Power processing circuits for wireless sensor nodes utilizing energy harvested from mechanical vibrations," in Proceedings of the 18th International Mixed Design of Integrated Circuits and Systems Conference (MIXDES '11), pp. 632-637, 2011. 

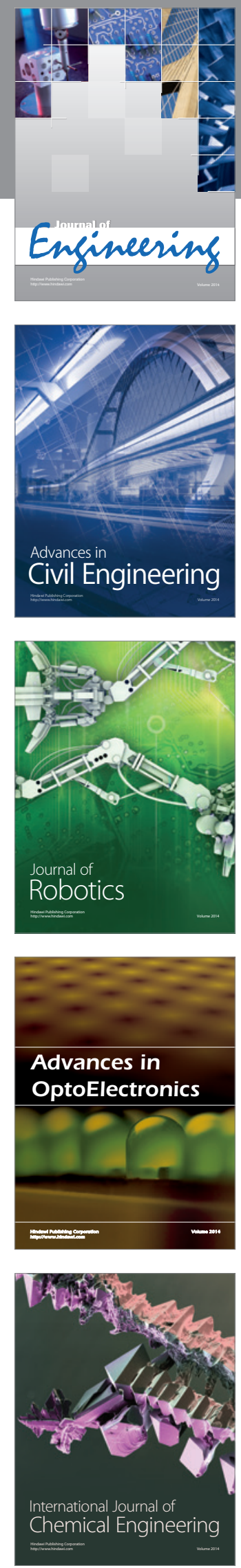

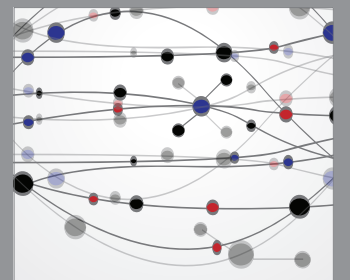

The Scientific World Journal
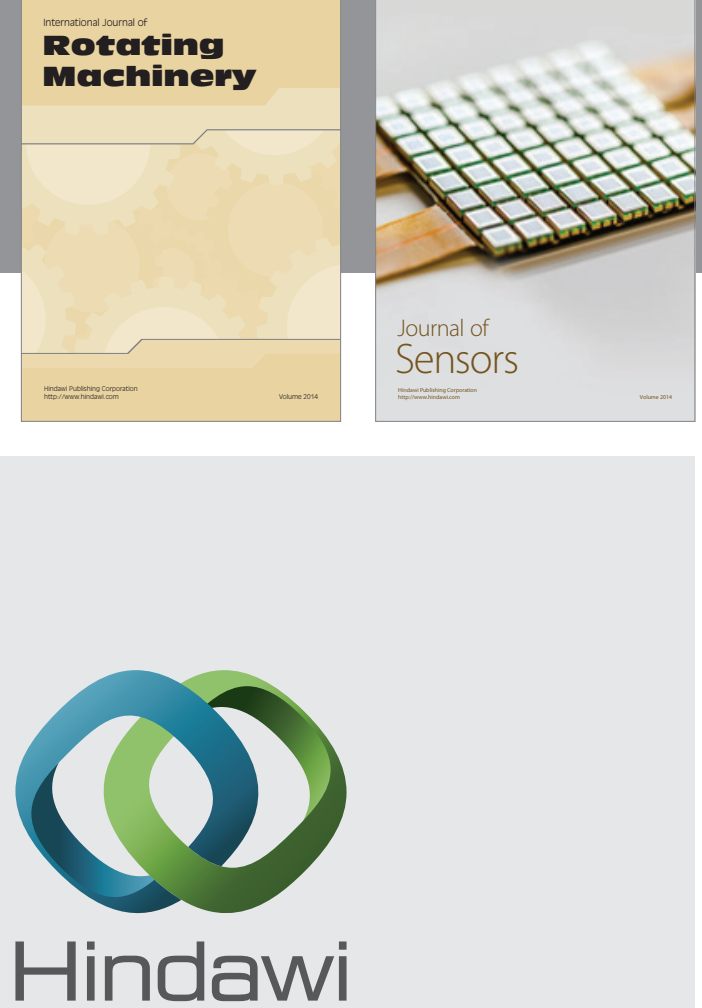

Submit your manuscripts at http://www.hindawi.com
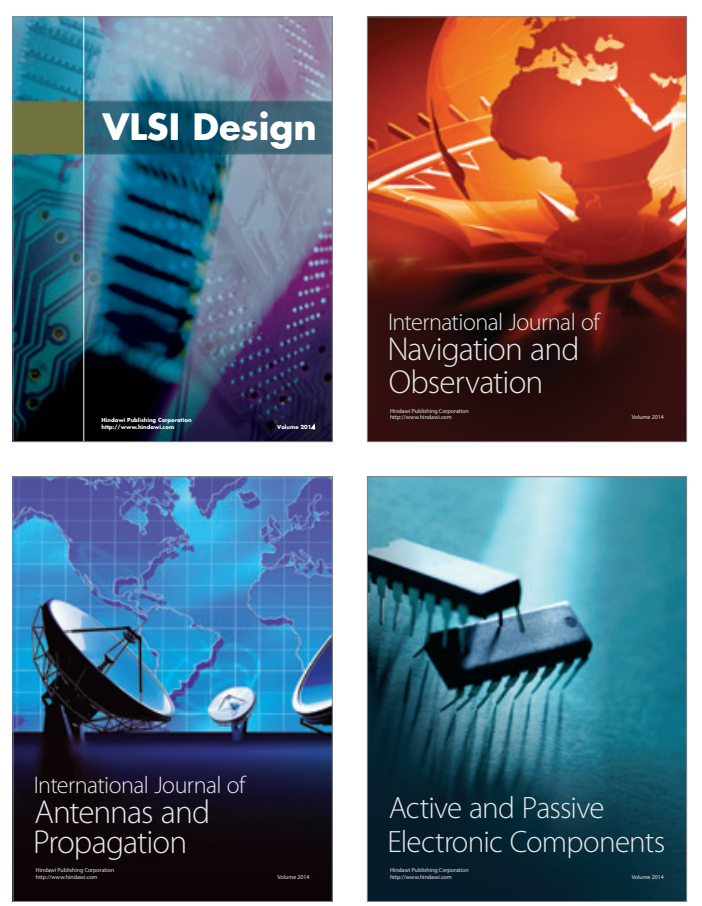
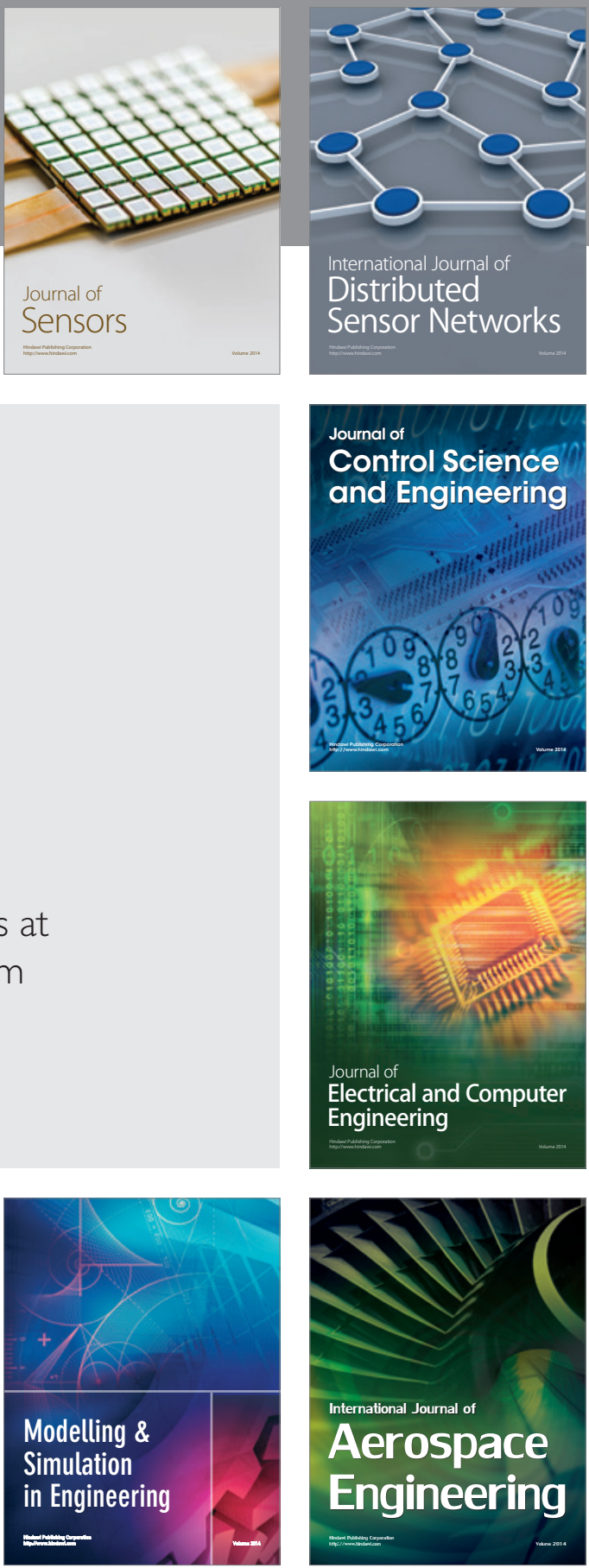

Journal of

Control Science

and Engineering
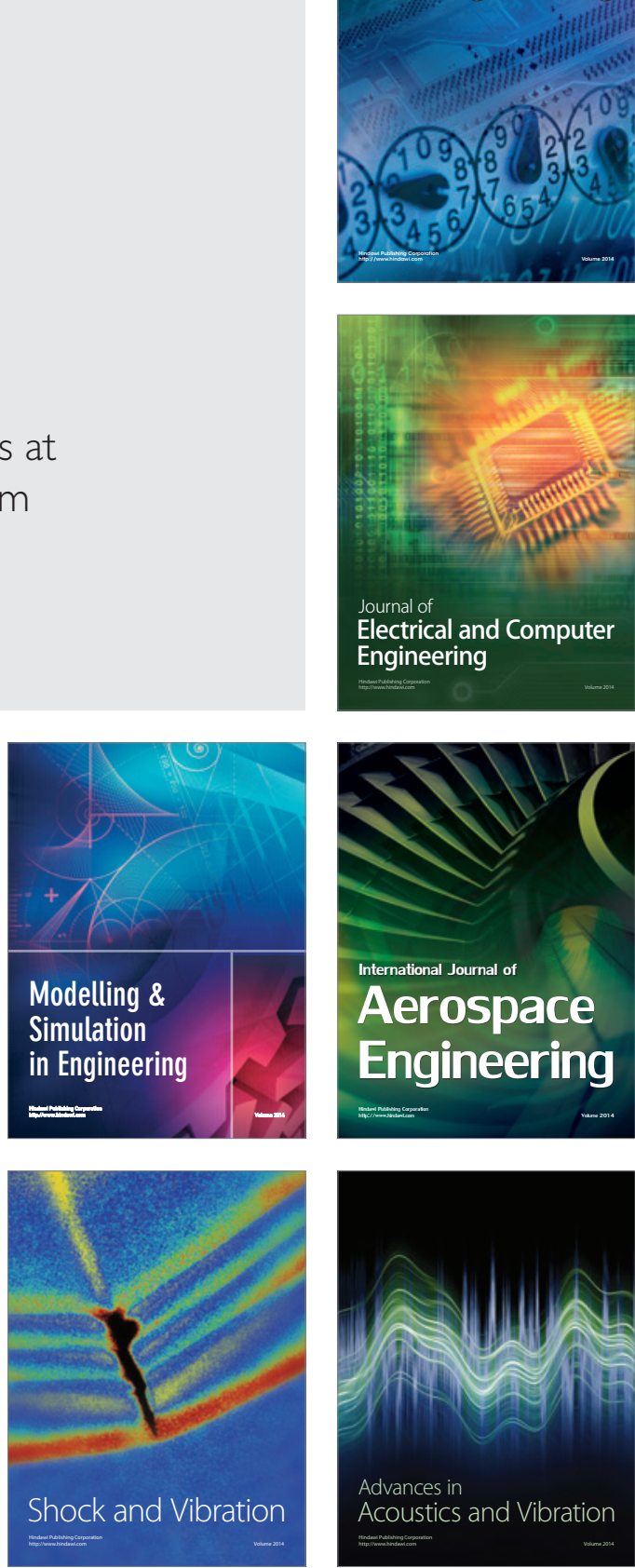